\title{
"PEDIDO" REGIO Y REPARTIMIENTOS EN CASTILLA: APROXIMACIÓN A PARTIR DEL EJEMPLO DEL ARZOBISPADO DE TOLEDO $(1399-1476)^{1}$
}

\author{
Pablo Ortego Rico \\ UNIVERSIDAD COMPLUTENSE DE MADRID
}

\begin{abstract}
RESUMEN
El presente artículo analiza los mecanismos de reparto del "pedido" regio establecidos en Castilla desde la conversión de esta carga en parte fundamental de los servicios otorgados por las Cortes a fines del siglo XIV. Para esta aproximación, llevada a cabo fundamentalmente a partir de ejemplos tomados de los repartos conservados para el arzobispado de Toledo, centraremos la atención en dos problemas fundamentales: por un lado, la cronología de la base utilizada para distribuir el "pedido" durante el siglo XV; y por otro, los mecanismos de corrección de los desequilibrios tributarios articulados por la Corona.
\end{abstract}

\section{ABSTRACT}

This article analyzes the distribution mechanisms of royal pedido set up in Castile, since the conversion of this tax in a fundamental part of the servicios granted by the Cortes at the end of the Fourteenth Century. For this approach, carried out with examples taken from the repartimientos preserved for the archbishopric of Toledo, we focus on two keys: on the one hand, the chronology of the quantitative base used to distribute the pedido in the Fifteenth Century; secondly, the mechanisms for correction of fiscal imbalances set up by the Crown.

PALABRAS CLAVE: pedido, arzobispado de Toledo, Castilla, fiscalidad real, siglo XV KEYWORDS: "pedido", archbishopric of Toledo, Castile, Royal taxation, Fifteenth Century

1. Este trabajo forma parte de los siguientes proyectos de investigación financiados por el Programa Estatal de Fomento de la Investigación Científica y Técnica de Excelencia, Subprograma Estatal de Generación de Conocimiento, del Ministerio de Economía y Competitividad: "El negocio de la fiscalidad: gestión tributaria, redes financieras y grupos de poder en la Corona de Castilla (1450-1550)" (HAR2013-45788-C4-1-P), dirigido por J. M. Carretero Zamora; y "Prácticas de comunicación y negociación en las relaciones de consenso y pacto de la cultura política castellana. Ca. 1230-1504" (HAR2013-42211-P), dirigido por J. M. Nieto Soria. 


\section{INTRODUCCIÓN}

La Reyna e el Infante fizieron llamar a los procuradores del Reino, e dixéronles que bien sabían en cómo avían otorgado para la guerra, al Rey don Enrrique, en Toledo, quarenta e çinco quentos de maravedís. E como quiera que en Toledo fincó sosesegado [sic] que fuese la mitad en moneda e la otra mitad en pedido, e agora querían mandar fazer repartimiento dello por el Reyno, porque se coxiese para la guerra, que les dezían si les paresçía que sería bien que se repartiese ansí ${ }^{2}$.

Con estas palabras, Álvar García de Santa María se hacía eco en su Cróni$c a$ de las negociaciones entabladas a comienzos de 1407 por los procuradores del reino para la recaudación del servicio de 45.000 .000 mrs. concedido al moribundo Enrique III en las Cortes reunidas en Toledo en diciembre de 1406 con el objetivo de reanudar la guerra contra Granada ${ }^{3}$. Más allá de que el texto sirva al cronista para introducir el debate surgido en aquel momento entre los representantes urbanos, polarizados en torno a los partidarios del modelo de distribución del servicio por mitades -"pedido" y "monedas"- propuesto en Toledo, que a la postre sería el aplicado, y los procuradores de aquellas ciudades que deseaban el reparto de la mayor parte de la ayuda en forma de "pedido" con el objeto de compensar las franquezas de "monedas" que disfrutaban algunas ciudades y villas, su contenido ilustra con claridad la consolidación de las mutaciones operadas en el modelo fiscal de la monarquía castellana desde fines del siglo $\mathrm{XIV}^{4}$. Estos cambios quedaron sustanciados fundamentalmente en dos fenómenos complementarios: por un lado, la sustitución del binomio alcabalas y "monedas", como sistema mixto de cobro habitual de los servicios otorgados por las Cortes, por un nuevo procedimiento de percepción basado en la recaudación de "pedidos" y "monedas"; por otro, la conversión de las alcabalas, concedidas por las Cortes por primera vez en 1342 a Alfonso XI con carácter extraordinario, y renovadas de forma periódica durante toda la segunda mitad del siglo $\mathrm{XIV}^{5}$, en renta ordinaria, cobrada para el rey sin necesidad de recurrir al concurso de la asamblea ciudadana desde 1398, fecha de su última concesión por parte de los representantes urbanos ${ }^{6}$.

2. J. M. CARriazo y Arroquia (1982), 59.

3. Sobre las Cortes de 1406 ver E. Mitre Fernández (1999), 137-141.

4. Análisis del sistema fiscal y hacendístico castellano entre 1369 y 1429 en M. Á. LADERo QuesADA (1999a), 401-483.

5. M. Á. LADERO QUESADA (1992), 785-801.

6. M. Á. LADERo Quesada (1999a), 420-425. Las quejas de los procuradores en las Cortes de Toledo de 1406 por la desvirtuación del carácter pactado y temporal que en origen habían tenido las alcabalas en P. ORTEGo Rico (2013a), 88-90. 
El análisis de ambos fenómenos, entendidos como parte de una profunda reforma del sistema fiscal castellano operada por Enrique III, todavía mal conocida en sus detalles, entraña grandes dificultades. En gran medida ello es consecuencia de la ausencia de fuentes diplomáticas o cronísticas que expliciten los mecanismos de negociación y las formas discursivas orquestadas en los años finales del siglo XIV por la Corona para establecer un nuevo consenso con la sociedad política del reino - especialmente con la representada en las Cortes ${ }^{7}$ - que permitiese sentar los cimientos de una maquinaria fiscal renovada con la que hacer frente a las crecientes necesidades de la monarquía, en el contexto de reforzamiento y extensión del poder real que caracterizó el reinado del tercer monarca Trastámara ${ }^{8}$. En este sentido, frente a la atención mostrada por la historiografía a la conversión de las alcabalas en renta ordinaria, plenamente justificada por la trascendencia intrínseca del fenómeno ${ }^{9}$, la sustitución de este mecanismo de percepción indirecto de una parte de los servicios de Cortes por una forma de tributación directa como el "pedido", que hasta el momento se había movido bajo cierta indefinición, apenas ha recibido una atención específica. Esto a pesar de la importancia de la carga para el análisis de las relaciones políticas entre Corona y concejos; de su interés para conocer aspectos demográficos a partir de los mecanismos de reparto de las cuantías otorgadas, así como la instrumentalización política de los desequilibrios y desigualdades que estos generaban; y de su importancia cuantitativa hasta la reforma del sistema extraordinario de tributación regia operada por los Reyes Católicos en $1478^{10}$.

7. El papel de las Cortes como escenario de representación del consenso político en la Castilla bajomedieval, y la problemática interpretativa que genera, ha sido destacado por J. M. NiETO SORIa (2010), 55-58.

8. Sobre los mecanismos políticos e instituciones (corregidores, Consejo Real, Cortes, Audiencia) que permiten hablar de este fenómeno ver E. Mitre Fernández (1980), 317 328.

9. M. Á. Ladero Quesada (1986), 195-214.

10. En relación al "pedido" son fundamentes las aportaciones específicas realizadas por F. J. Romero Romero (1997); J. D. GonzÁlez ArCe (2010), 11-40; J. RodríGuez SARria (2012), 79-98; J. M. Triano Milán (2013), 361-395; J. RodríGuez SARria, J. M. Triano Milán (2015), 329-352. Agradezco a los autores de este último trabajo que me hayan permitido consultarlo antes de su publicación. Sobre el cambio en el modelo tributario de la fiscalidad extraordinaria que supuso la sustitución de los antiguos servicios de Cortes -otorgados hasta 1476- por la contribución ordinaria de la Hermandad, establecida en 1478, ver P. ORTEGo Rico (2015), 275-323 y la bibliografía allí recogida. 


\section{LOS INICIOS DEL "PEDIDO" REGIO COMO FORMA DE COBRO DE LOS SERVICIOS DE CORTES (DE JUAN I A ENRIQUE III)}

La voz "pedido", cuyos orígenes hay que rastrear en el antiguo petitum generalizado desde el siglo XII en Castilla ${ }^{11}$, ofrece algunas dificultades de interpretación en el último tercio del siglo XIV, resueltas acertadamente por I. García Díaz, que considera equivalentes los términos "servicio"-localizado, por ejemplo, en la documentación murciana de las décadas de 1370-1380- y "pedido", presente en las fuentes a partir de la década de 1390, aunque con antecedentes desde $1367^{12}$. A pesar de las fluctuaciones observadas en la nomenclatura, lo cierto es que ambos vocablos - "pedido" y "servicio"- remiten en el último tercio siglo XIV a una realidad semántica múltiple, aunque referida, con un carácter general, a aquellas cargas solicitadas de forma extraordinaria por el monarca -también por algunos señores ${ }^{13}$ - a sus vasallos pecheros, recaudadas a partir de mecanismos de tributación directa por los concejos como instancias políticas con las que el poder beneficiario establecía la interlocución a efectos de cobro ${ }^{14}$.

Este carácter directo del "pedido", percibido mediante la distribución de la carga, habitualmente conocida de antemano, entre las unidades fiscales obligadas a tributar (fuegos, humos, hogares, casas), se explicita en algunos documentos anteriores a la reforma en los servicios de Cortes operada por Enrique III. Ya en las Cortes de Soria de 1380 los procuradores denunciaron ante Juan I los atropellos cometidos por algunos caballeros y escuderos que arrendaban las alcabalas de los arrendadores en sus jurisdicciones, y posteriormente "las echauan e derramauan en las sus tierras en cada casa asy commo pidido". La

11. C. SÁnchez Albornoz (1965), 483-519. M. Á. Ladero Quesada (2011), 51-52.

12. I. García Díaz (1989), 846-847. En el mismo sentido se han expresado M. Á. LADERo Quesada (2009a), 422 y D. Menjot (1979), 96-98.

13. En relación a los "pedidos" señoriales, bien documentados para distintos territorios, sabemos que cuando en las Cortes de Guadalajara de 1390 Juan I estableció las exenciones tributarias disfrutadas por la clerecía se incluyó una ley de Enrique II guardada en la Audiencia Real, según la cual se eximía a los clérigos de contribuir con el concejo "en los pedidos que nos demandamos o demandáremos al concejo, de que fue o fuere nuestra merced de nos seruir dellos, e otrosy en los pedidos de qual quier otro sennor". Cortes (1863), vol. 2, 451-452.

14. Ver la voz "pedido" elaborada por Antonio Collantes de Terán para el Glosario Crítico de Fiscalidad Medieval coordinado por D. Menjot, P. Verdés Pijuán y M. Sánchez Martínez, bajo el patrocinio del CIHAM-UMR 5648 y la Institutión Milá y Fontanals del CSIC.http://www.1minut.info/glosariofiscalidad.org/index.php?option=com_content\& view $=$ article $\& \mathrm{id}=62 \&$ Itemid $=71 \&$ lang $=$ es 
queja planteada ponía el acento en una práctica, extendida especialmente en los ámbitos rurales que, como es bien sabido, perseguía la conversión de un impuesto indirecto sobre las compra-ventas y otras transacciones económicas, como las alcabalas, en una carga directa, con el objeto de ampliar el espectro de obligados tributarios. Por ello, los representantes urbanos solicitaban a Juan I "que fuesen pididas las dichas alcaualas al que las deuiere, e que non sean derramadas por pidido nin en otra manera", a lo que el rey accedió ordenando que solo pagasen el impuesto aquellos "que conpraren algunas cosas de que ayan a pagar alcauala"15. Poco después, en 1385, el monarca recordaba a sus contadores la consideración del "pedido" como "pecho" junto a otras cargas como la martiniega, la fonsadera, la "yuntería" o la "andaduría", para zanjar la disputa relativa a ciertos exentos de Ávila a los que se quería hacer tributar $^{16}$.

Otros datos se refieren a los mecanismos de aprobación de estos "pedidos" extraordinarios, la fijación de su cuantía, la forma de reparto y cobro, y su grado de mediatización por parte de las Cortes. En el otoño de 1385 los procuradores reunidos en las Cortes de Valladolid concedían, previa petición regia, un "pedido" extraordinario para paliar las dificultades hacendísticas y militares derivadas de la derrota de Juan I en Aljubarrota (14 de agosto de 1385), con toda una serie de condiciones relativas a la cuantía del tributo, forma de pago -según la hacienda del contribuyente, previa elaboración de padrones de "cuantías" por los concejos-, número de exentos, y sistema de recaudación. Aunque esta concesión -la primera bajo esta nomenclatura sobre la cual tenemos datos precisos- fue sustituida un mes después por un empréstito de 10.000.000 mrs., a recaudar igualmente por los concejos, muchos de los fundamentos tributarios observados en el futuro para el cobro del "pedido" ya tienen reflejo en el cuaderno de condiciones aprobado en $1385^{17}$.

Más adelante, una de las peticiones formuladas por los procuradores reunidos en las Cortes de Palencia de 1388, relativa al reparto de las indemnizaciones acordadas entre Juan I y Juan de Gante, duque de Lancáster, para alcanzar la paz tras la invasión de Galicia por las tropas inglesas, y facilitar la renuncia al trono castellano del pretendiente extranjero a cambio de 540.000

15. Cortes (1863), vol. 2, 306. La cursiva es nuestra.

16. Albalá de Juan I a los contadores mayores en el que se recuerda que los padres de cuarenta "mozos de nómina" servidores del coro de la iglesia de Ávila estaban excusados del pago de cualquier pecho, según constaba en ciertos privilegios confirmados por Enrique II. C. Luis LóPEZ y G. DEL SER QuiJano (1990), 102-103.

17. El contenido del cuaderno del "pedido" de 1385 ha sido analizado por M. GonzÁLez JiMÉNEZ (1979), vol. I, 33-44. 
francos de oro, incluye una mención a la necesidad de que el rey, en caso de haber procedido ya al cobro y redistribución de otras cantidades solicitadas previamente al reino, diese cuenta "de lo que rendieron todos los pechos e derechos et pedidos" solicitados desde las Cortes de Segovia de 1386, y de su gasto, tal y como se había comprometido a hacer en aquel momento, lo cual evidencia la continuidad de este mecanismo fiscal con posterioridad a $1385^{18}$. De nuevo, en 1388 tenemos costatado a través de la documentación murciana el cobro de un "servicio" para hacer frente a las pagas del duque de Lancáster ${ }^{19}$ que, sin embargo, en las fuentes abulenses recibe el nombre de "pedido" ${ }^{20}$, lo cual ratifica la correspondencia de ambos conceptos ya apuntada.

Por otra parte, "pedidos"/“servicios" y "empréstitos", sin ser figuras equivalentes, compartían a fines del siglo XIV algunos rasgos comunes, entre ellos su carácter directo y extraordinario, o su forma de percepción por parte de los concejos previa distribución por parte de la Corona y su equipo de hacendistas de las cuantías solicitadas entre las unidades territoriales de reparto consideradas. Sin embargo, existían también notables diferencias: mientras los "pedidos" o "servicios" debían contar para su aprobación con el consentimiento de las Cortes, los "empréstitos" -cuyo importe debía ser teóricamente reintegrado posteriormente con cargo a otras rentas, algo que no siempre sucedía- eran resultado de la voluntad regia, sin que habitualmente se observe la injerencia de la asamblea ciudadana en su otorgamiento y fiscalización ${ }^{21}$. De lo que no cabe duda es que ambas cargas alcanzaron gran impopularidad en el contexto de fuerte incremento de la presión fiscal que marcó el reinado de Juan $\mathrm{I}^{22}$. Así se explicita en una de las condiciones incluidas en el ordenamiento dado en

18. Cortes (1863), vol. 2, 408-409.

19. I. García DíAz (1989), 850.

20. "Nos, los del conseio de nuestro señor el rey, visto un pleito que es entre los cavalleros que dicen castellanos de Ávila e las dueñas viudas, mugeres que fueron de cavalleros castellanos, que al tiempo de su finamiento devían gozar de los previleios que aiuso diremos, e sus procuradores en su nombre, de la una parte, e los pecheros de la dicha cibdad de Ávila e sus arrevales e pueblos de su tierra, e sus procuradores en su nombre, de la otra, sobre razón que la parte de los dichos pecheros demandavan a los dichos cavalleros e viudas que pagasen con ellos en el pedido del año pasado del nascimiento del nuestro señor de mil e trecientos e ochenta e ocho en lo que les copo a pagar, demás del abono de las doblas que pagaron el dicho año; e la parte de los dichos cavalleros e dueñas viudas decían que no eran tenudos de lo pagar, pues en ello non pagavan los cavalleros de la dicha cibdad que decían serranos" [...]. G. DEL Ser QuiJano (1998), 339-340.

21. No obstante, la Corona trató de crear unas mínimas condiciones de consenso con el reino, aunque solo fuera porque para el cobro efectivo de los empréstitos era imprescindible la colaboración activa de los concejos. Sobre los empréstitos durante la época Trastámara ver C. Olivera Serrano (1991), 317-327.

22. M. Á. LADERo Quesada (2009a), 412-420. 
las Cortes de Madrid de 1391 para el regimiento del reino durante la minoría de Enrique III, que facultaba a los miembros del "revolucionario" Consejo de Regencia nombrado -en el que se integraban catorce representantes urbanos, en dos turnos semestrales- a establecer tributos extraordinarios al margen de los otorgados por las Cortes y ayuntamientos, siempre que mediara "caso muy necesario de guerra", se contara con la autorización de los procuradores de las ciudades y villas que formaban parte de dicho Consejo, y que su montante fuera recaudado en forma de "monedas, e non pedidos nin enprestidos en general nin en especial"'23.

Por lo tanto, al iniciarse en octubre de 1390 de forma inesperada el reinado de Enrique III, tras el accidente ecuestre sufrido por su padre, el cobro de "pedidos" era una realidad firmemente asentada en la práctica fiscal castellana. Quizás ello fuese consecuencia de la necesidad de sustituir a partir de 1386 el régimen de empréstitos establecido por Juan I para solventar sus agobios hacendísticos, cuya legitimidad no nacía de un consenso efectivo alcanzado con la sociedad política del reino expresado a través de las Cortes, por un nuevo mecanismo fiscal: el cobro de unos "servicios", complementarios de "monedas" y "alcabalas", denominados definitivamente "pedidos" en la década de $1390^{24}$. Se trataba de un instrumento mucho más efectivo en términos políticos y hacendísticos, en tanto su concesión partía de la aquiescencia de la asamblea ciudadana, y ya no sería necesario reintegrar posteriormente las sumas percibidas al no ser categorizadas como préstamos, sino como expresión de la obligación de auxilium económico que todo súbdito tenía respecto de su monarca.

En este sentido, el reinado del Rey Doliente se caracterizó, como adelantábamos, por una reorganización definitiva del sistema de cobro de las cuantías extraordinarias otorgadas por los procuradores que llevó, a partir de 1399, a considerar su percepción bajo la doble forma de "pedidos" y "monedas", consolidada definitivamente una vez convertidas las alcabalas en renta ordinaria, según figuran explícitamente ya en un documento real de febrero de $1399^{25}$. Así, sabemos que frente a los subsidios concedidos entre 1393 y 1398 bajo la

23. Cortes (1863), vol. 2, 489. La cursiva es nuestra.

24. I. GARCía DíAz (1989), 853-854.

25. Se trata del reparto del "pedido" de 1399 en determinadas localidades del arzobispado de Toledo, expedido el 4 de febrero de 1399, en el cual se recuerda cómo en el ayuntamiento celebrado previamente en Madrid se había aprobado el cobro de seis "monedas" y "pedido", "demás de las alcaualas e otras rrentas ordinarias que de cada año yo he de auer en los dichos mis rregnos". A. Millares Carlo y E. Varela Hervías (1932), 318. 
forma tradicional de "monedas" y alcabalas ${ }^{26}$, y las concesiones puntuales de "pedidos" de las que tenemos noticia para los años $1397^{27}$ y $1398^{28}$, un ayuntamiento celebrado en Madrid, quizás en los últimos meses de $1398^{29}$, otorgaba a Enrique III para el mantenimiento de la familia real, la defensa de la frontera con Granada, y la prosecución del conflicto con Portugal, reanudado en 1396 tras la toma lusa de Badajoz, un servicio de doce "monedas" y "pedido" pagadero en $1399^{30}$. Al parecer, Enrique III se comprometió en el transcurso del mismo ayuntamiento, que apenas ha dejado rastro documental quizás por la baja afluencia de representantes urbanos, a hacer efectivo únicamente el cobro de la mitad del servicio aprobado - esto es, medio "pedido" y seis "monedas"-

26. Las concesiones conocidas son las siguientes: alcabala "veintena" (5\%) y seis "monedas" en las Cortes de Madrid de 1393; seis "monedas" anuales por dos años y alcabala "veintena" en las Cortes de Medina del Campo de 1394; diez "monedas" en las Cortes de Segovia de 1396; doce "monedas" y alcabala "decena" (10\%) en las Cortes de Toledo de 1398. M. Á. LADERo Quesada (2009a), 421-422.

27. En 1397 las Cortes de Ávila aprobaron un "pedido", cuyo reparto por localidades se conoce para Murcia. M. L. Martínez CARrillo (1980), 39, 47 y 52. De igual forma, una carta dada por Enrique III el 18 de febrero de 1398 se refiere al "serviçio e pedido que lançé a los mis rregnos este otro año que agora pasó de mill e trezientos e noventa e syete años", cuya recaudación había dado lugar a conflictos y pleitos a la hora de determinar la condición y número de exentos, y si las exenciones de "monedas" debían hacerse extensibles a los "pedidos". En el documento el rey ordena que se observe la ley dada por Juan I en las Cortes de Briviesca de 1387. G. DEL Ser Quijano (1998), 70-72.

28. Sobre el "pedido" aprobado en 1398 tenemos un albalá dado por Enrique III a los oidores de la Audiencia Real el 29 de mayo de 1398 en relación a las quejas planteadas por el obispo de Burgos por los agravios y desafueros cometidos contra los clérigos de su obispado, a los cuales algunos concejos querían hacer contribuir en los pechos que recaudaban. En el documento el rey ordena a los oidores librar cartas de privilegio que ratifiquen el contenido de las leyes al respecto dadas por Enrique II y Juan I, "en que declararon las cosas en que devian pagar los clerigos con los conçejos e en quales non", así como la expedición de "las cartas que menester ovieren en que les sea guardado el quaderno de la ordenança que yo mande fazer este año sobre razon deste pedido que mande pagar a los de los mis regnos". L. SERRANo (1907), 274-275. La cursiva es nuestra.

29. Sobre la dificultad de ubicar cronológicamente este ayuntamiento celebrado en Madrid, a partir de los datos del itinerario de Enrique III, y las controversias que este hecho genera ver F. A. Veas Arteseros (2003), 217. E. Mitre Fernández (1999, 132-133) se decanta por su celebración poco antes de las Cortes de Segovia, en torno al mes de mayo de 1399.

30. La noticia más antigua sobre este servicio data de febrero de 1399. A. Millares Carlo y E. Varela Hervías (1932), 318-319. Este servicio debía ser similar, en lo que a mecánica recaudatoria se refiere, a otro aprobado teóricamente en 1398, que probablemente nunca se llegó a cobrar. 
$\mathrm{y}$, solo en caso de necesidad, ordenar la percepción de la mitad restante, que finalmente, quedó rebajada a cuatro "monedas" 31 .

Más allá de estos detalles y condiciones, que debemos entender en el marco de las negociaciones establecidas por la Corona con los representantes del reino para alcanzar un escenario de consenso que facilitase la aprobación del servicio, sabemos que los procuradores reunidos en Madrid solicitaron al rey "que mandase rrepartir vna quantía del dicho seruiçio e pedido, porque si tanto non fuese mester commo el año pasado, que se non rrepartiese" 32 . Esta mención al reparto de la carga a percibir en 1399, que ha pasado bastante inadvertida, nos sitúa ante la praxis fiscal definida para el cobro del "pedido", que atravesaba, con carácter general, por las siguientes fases, perfectamente consolidadas ya durante el siglo XV: otorgamiento del servicio por parte de las Cortes o ayuntamiento; reparto por la Corona y sus oficiales hacendísticos -habitualmente los contadores de rentas- de la cuantía establecida para el "pedido", no siempre especificada en los otorgamientos, según circunscripciones fiscales, y dentro de estas por unidades menores (concejo, jurisdicción señorial, villa y tierra) a las que se asignaba un cupo global, teóricamente conforme a su población pechera y la riqueza de esta; notificación a los concejos de las

31. Se conserva, por ejemplo, una carta de Enrique III, fechada en Segovia el 20 de mayo de 1399 , en la que se insta al concejo de Burgos, y a las villas y lugares de su merindad, a recaudar, para el pago del ejército mandado reunir, cuatro "monedas" de las seis segundas "monedas" aprobadas por el ayuntamiento celebrado en Madrid, en el cual se habían concedido un "pedido entero" y doce "monedas" para proseguir la guerra contra Portugal. En el documento leemos lo siguiente: "Bien sabedes en como en el ayuntamiento que yo fize en Madrit este año de la data d'este mi carta con el infante don Ferrando, mi hermano, e el Cardenal d'España, e el arçobispo de Toledo, e los otros perlados de los mis regnos, e los cavalleros del mi Consejo, e los procuradores de algunas çibdades e villas de los dichos mis regnos fue ordenado que para continuar la guerra que yo he con el adversario de Portogal, que los dichos mis regnos que me sirviesen con un pedido entero e con doze monedas, segund el año que pasó de mill e trezientos e noventa e ocho años, e que luego de presente mandaré coger la mitad del dicho pedido e seys monedas, e sy más fuere menester que mandase coger medio pedido e las otras seys monedas o lo que más cunpliese a mi serviçio e fuese menos dapno de los dichos mis regnos". Archivo Municipal de Burgos (en adelante AMB), Sección Histórica, núm. 2742. El documento también es manejado por E. Mitre Fernández (1999), 133. De nuevo, el 12 de julio de 1399 Enrique III se volvía a dirigir a los concejos de las merindades de Burgos, Candemuño, Cerrato, Castrojeriz, Villadiego, Liébana y Pernía con Aguilar de Campoo, Santillana, Castilla Vieja, Bureba, Rioja y Santo Domingo, en relación a la recaudación de cuatro "monedas" de las seis "postrimeras" que faltaban por coger de las doce "monedas" y "pedido" otorgados. AMB, Sección Histórica, núm. 2743.

32. A. Millares Carlo y E. Varela Hervías (1932), 318-319. 
cantidades distribuidas mediante real provisión, para su cobro efectivo ${ }^{33}$; reparto local de la carga, especialmente en aquellos casos en los cuales el cupo afectaba a jurisdicciones completas (por ejemplo una villa o ciudad y su tierra); percepción del montante, mediante tributación directa y sin arrendamiento de la carga, previa elaboración de padrones "de cuantía” y repartimiento; entrega del producto de la recaudación al oficial regio -tesorero, recaudador mayor- encargado de actuar como correa de transmisión entre el concejo y los beneficiarios de las órdenes de pago emitidas desde la Corona ${ }^{34}$.

Aunque los especialistas han centrado preferentemente su atención en los complejos sistemas de cobro orquestados por los concejos para hacer frente a las deudas tributarias contraídas con la Corona $^{35}$, como parte del análisis de la incidencia del fisco regio en la articulación de las relaciones políticas y socia-

33. Análisis diplomático de esta tipología documental en A. Romero MarTínez (1998), 3437. Entre los papeles simanquinos se conservan los registros y formularios de algunas de estas provisiones. Por ejemplo, la dada en Astudillo el 21 de julio de 1451 al concejo de Sigüenza y las villas de su obispado relativa al servicio otorgado por las Cortes para el bienio 1451-1452 y la necesidad de anticipar algunos plazos. Archivo General de Simancas (en adelante AGS), Escribanía Mayor de Rentas (en adelante EMR), leg. 4-1, f. 72. Provisión real informando a Burgos de la necesidad de pagar en 1456 el "pedido" que se debía repartir con 16 "monedas" en el reino en 1456, según había quedado aprobado por las Cortes en 1455 en AGS, EMR, leg. 5-1, ff. 1-2. Provisión notificando a Burgos el 24 de julio de 1462 las cantidades que correspondía pagar del "pedido" otorgado junto a 16 "monedas" por las Cortes para 1462 en AGS, EMR, leg. 17, f. 1. Provisión de Enrique IV de 1474, sin mes ni día, en la que ordena pagar a los concejos del obispado de Sigüenza los mrs. del "pedido líquido" de 30.000.000 mrs. repartidos para 1475 en AGS, Expedientes de Hacienda (en adelante EH), leg. 2, f. 149. Es interesante señalar el reparto que a nivel interno existía entre los oficios integrados en la Contaduría de la gestión de la información remitida a las distintas circunscripciones del reino, dentro de una dinámica administrativa que impide concebir la estructura hacendística de la monarquía castellana como un todo orgánico en función de las redes de dependencia personal establecidas en torno a cada uno de los oficiales. Por ejemplo, en 1451 y 1452 las cartas de los "pedidos" y "monedas" aprobados por las Cortes se repartieron "a fazer en los ofiçios" de García [Fernández] de Alcalá -quedó a cargo de Sigüenza, Talavera, Madrid, Guadalajara, Cuenca, Badajoz, Córdoba y Cartagena- y de Fernán Yáñez de Galdo -quedó a cargo de Osma, Toledo, Calatrava, Alcaraz, Plasencia, Coria y Cáceres, Sevilla y Jaén-. Ambos oficiales eran contadores del rey. AGS, EMR, leg. 4-1, ff. 60 y 122. En 1451 García Fernández de Alcalá era contador de rentas. AGS, Mercedes y Privilegios, leg. 7, f. 147. F.P. CAÑAS GálveZ (2012), 304-306. La importancia asignada a la notificación a los concejos de esta información hizo que desde la propia Contaduría se confeccionase un registro de las personas encargadas de "presentar e notificar e traher diligençias" de las cartas remitidas a cada distrito tributario. Muchas de estas personas -a tenor de los registros conservados para los años 1450-1452- se encontraban estrechamente relacionadas con los círculos financieros y de la administración hacendística. Cartas del "pedido" de 1450 en AGS, EMR, leg. 4-1, f. 4; cartas del "pedido" y 12 "monedas" de 1451 en AGS, EMR, leg. 4-1, f. 60; cartas del "pedido" y "monedas" de 1452 en AGS, EMR, leg. 4-1, f. 122. Ver P. Ortego Rico (2013b), 528-529.

34. M. Á. LADERO Quesada (2009b), 201-208.

35. A. Romero Martínez (1999); J. RodríGuez SARria (2012), 79-97. 
les en el ámbito local ${ }^{36}$, el estudio de la fase inicial de distribución de la carga fiscal mediante "repartimientos" elaborados por los oficiales regios -es decir, bajo el control de la Corona- también puede arrojar luz sobre otros aspectos complementarios de la mecánica fiscal, entre ellos la configuración del espacio tributario, el peso demográfico relativo que se deduce de las cuantías repartidas, los problemas derivados de la falta de revisión de las bases cuantitativas sobre las cuales se realizaba la distribución de los cupos tras cada nuevo otorgamiento de servicios por las Cortes, o las relaciones políticas estrechadas entre Corona y concejos a partir del cobro de esta carga y las incidencias a que daba lugar. Con este fin, proponemos el estudio de algunos aspectos referidos a los "repartimientos" del "pedido" conocidos para el ámbito del arzobispado de Toledo entre 1399 y 1476, como gran ámbito territorial apenas analizado desde esta perspectiva, frente a los avances en la investigación llevados a cabo en otros espacios fiscales como el reino de Murcia, el arzobispado de Sevilla o Galicia $^{37}$. En esta ocasión, nos ocuparemos únicamente de dos elementos fundamentales: por un lado, la concreción del contexto cronológico en el cual se estableció la base vigente para la realización de los distintos repartos conservados hasta 1476, pues solo así se pueden comprender las quejas planteadas contra el sistema durante los reinados de Juan II y Enrique IV; y por otro, las medidas de corrección incorporadas por la Corona, de manera insuficiente, a lo largo del período considerado.

\section{EL REPARTIMIENTO DE 1399, LA FIJACIÓN DE NUEVOS CUPOS Y LA PESQUISA DE LOS “HUMOS" DEL REINO DE 1409}

Como se ha comprobado, el recurso al "pedido" como forma de cobro de los servicios de Cortes junto a las "monedas" se encontraba plenamente operativo en 1399. Para este año conservamos el primer repartimiento detallado

36. Los trabajos dedicados al caso murciano son, en este sentido, prototípicos. D. Menjot (1999), 223-257; (1997), 125-144; (1978), 1-43; y M. L. Martínez Carrillo (1980), 35-82; (1987-1988), 273-332.

37. Para Murcia se conocen los cupos asignados en los repartimientos de 1397, 1399, 1397, 1408, 1409, 1410 y 1419, 1422, 1425. M. L. Martínez Carrillo (1980), 47; (19871988), 312. Sobre el "pedido" en el arzobispado hispalense ver el análisis, desde la perspectiva de la geografía tributaria, llevado a cabo por J. M. Triano Milán (2013), 361395, y los datos, vinculados con aspectos demográficos, aportados por M. Á. LADERO QuesADA (1969), 479-497. El repartimiento del "pedido" en Galicia ha sido estudiado por C. Olivera Serrano (2004), 363-374. 
por localidades del arzobispado de Toledo, contenido en el traslado de una carta real, expedida desde Toledo el 4 de febrero de 1399, y custodiada en el Archivo de Villa de Madrid ${ }^{38}$. Este reparto tiene unas características formales que lo alejan de los conocidos para fechas posteriores. En primer lugar, la circunscripción base teórica que se tiene en cuenta es el arzobispado, frente a la fragmentación del territorio fiscal en arcedianazgos (Guadalajara, Madrid, Talavera, Toledo, Calatrava y Alcaraz), que se observa en los repartos del "pedido" conservados a partir de $1442^{39}$. Por otra parte, apenas se incluyen 69 localidades o grupos de localidades integradas mayoritariamente en los arcedianazgos de Toledo y Madrid ${ }^{40}$, con escasa presencia de lugares y villas localizados en los arcedianazgos de Talavera y Calatrava, y una ausencia total de núcleos adscritos a los arcedianazgos de Guadalajara y Alcaraz ${ }^{41}$, que hemos de suponer figurarían en otras cartas de reparto enviadas a los concejos, que no se han conservado. Por lo tanto, la validez de este repartimiento para conocer de forma global el poblamiento relativo de este espacio es muy limitada, frente a las mayores posibilidades que ofrece la detallada toponimia incluida en los repartos de época de Juan II. Finalmente, se detecta una distribución de las "cabezas de pedido" - esto es, de las unidades territoriales de reparto tributario- siguiendo un patrón que tiende a agrupar algunas poblaciones y términos conforme a criterios variables (escasos efectivos demográficos, proximidad, dependencia jurisdiccional) que, salvo excepciones, no tuvieron continuidad en el futuro.

En cuanto al significado de las cuantías, y su correspondencia con la realidad demográfica poco se puede avanzar, ya que desconocemos el número de mrs. repartido por pechero, suponiendo que ese fuera, como parece, el criterio

38. A. Millares Carlo y E. Varela Hervías (1932), 317-324. A tenor de los datos conocidos para el reino de Murcia en relación al "pedido" de 1397, quizás no fuese el primer repartimiento confeccionado a instancias de la Corona. M. L. Martínez Carrillo (1980), 47.

39. Los primeros monarcas de la dinastía Trastámara mantuvieron como unidad fiscal, al menos de tesorería y de recaudación, el ámbito conjunto del arzobispado de Toledo, tal y como evidencian, por ejemplo, distintas menciones a tesoreros y recaudadores incluidas en la cuenta dada por el camarero de Juan I Diego López de Estúñiga entre agosto de 1379 y fines de noviembre de 1380 . Por ejemplo, en 1378 y 1379 era recaudador en el arzobispado de Toledo, sin especificar renta, Pero García de Peñaranda. Como tesorero mayor de Enrique II en el reino de Toledo figura Gómez García. M. L. de Villalobos Martínez-Pontremuli (1983), 163-164 y 171.

40. Para su correcta identificación se ha seguido el exhaustivo estudio de J.-P. MoLÉNAT (1997), habida cuenta de que la transcripción del documento llevada a cabo por A. Millares Carlo y E. Varela Hervías podría contener errores de lectura.

41. La localización de cada localidad en términos de geografía eclesiástica en F. J. HeRnáNDEZ (1993), 215-238. 
empleado a la hora de distribuir la carga. La agrupación por "cuartiles" de las cifras, es decir, en función de los tres valores que dividen al conjunto de datos ordenados en cuatro partes porcentualmente iguales $(660,1518$ y $3.300 \mathrm{mrs}$.), puede aportar algunas claves. Así, un $25 \%$ de las cifras se sitúa en valores iguales o inferiores a $660 \mathrm{mrs}$., que debemos asignar a núcleos rurales escasamente poblados (alquerías, ventas...) o en vías de despoblación. Un 50\% se localiza en cifras entre los $660 \mathrm{mrs}$. y los $3.300 \mathrm{mrs}$., quizás correspondientes a lugares rurales con un poblamiento estable o más consolidado, aunque en ocasiones, la propia debilidad demográfica pudo favorecer la asignación conjunta a varios enclaves de cupos situados en este arco. Así se observa en el caso de la suma repartida conjuntamente a Pejinas de la Sisla, Santa María de Pejinas, Casasbuenas y Almudilla, que tan solo alcanzó los 742 mrs., o en el caso de Algurilla, Renales, Villamocén y Argance, con un cupo global de 709 mrs. Por encima de los 3.300 mrs. encontramos otro $25 \%$ de localidades -0 grupos de localidades comarcanas- de tamaño medio, además de territorios jurisdiccionales a los que se asignaron cupos conjuntos, que posteriormente la villa que ejercía como cabeza de la jurisdicción se encargaría de repartir conforme a sus intereses. Es el caso de Montalbán y su tierra con Menasalbas (7.735 mrs.), de la Vicaría de La Puebla de Alcocer con Siruela (30.800 mrs.), y de Madrid y su tierra (46.200 mrs.), que contribuía con el cupo más elevado de los distribuidos.

Finalmente, la ausencia de la ciudad de Toledo en el repartimiento no debe sorprender, habida cuenta de la exención de "pedidos" y "monedas" que disfrutaban los vecinos de la ciudad gracias a una acumulación de privilegios otorgados entre los reinados de Alfonso X y Fernando IV ${ }^{42}$. De hecho, en la nómina de ciudades y villas exentas incluida en el "cuaderno" de arrendamiento de "monedas" de 1381 figura la franqueza disfrutada por todos los poseedores de casas situadas dentro de Toledo que tuviesen mujer e hijos residentes "continuadamente del muro adentro" administrativa del siglo XV, que también hacía extensible la franqueza a los "pedidos", aunque en condiciones poco claras -como señalamos la ciudad no figura en los repartimientos del "pedido"-, quizás amparadas en el privilegio dado por Fernando IV en abril de 1309 en el que se extendía la franqueza

42. Sobre la exención tributaria de Toledo remitimos a las consideraciones formuladas en la tesis doctoral de P. ORTEGo Rico (2013b), 500-501. Los privilegios que se refieren a las exenciones de "monedas" y de "pechos" -el "pedido" lo era- en R. IzQuiERDo BENITO (1990), docs. 29, 31, 34, 37, 38, 39 y 48.

43. D. Menjot (1978), 363. 
tributaria a todos los vasallos y apaniaguados de los vecinos de la ciudad, declarados exentos del pago de pecho alguno, aunque no de "moneda forera" ${ }^{4}$.

Tabla 1. Repartimiento del "pedido" en algunas localidades del arzobispado de Toledo (1399)

\begin{tabular}{|c|c|}
\hline Unidad de reparto tributario & Cuantía (mrs.) \\
\hline Collación de Monesterio & 2.310 \\
\hline Mascaraque ["Maxarrique"] & 1.320 \\
\hline Ajofrín & 8.250 \\
\hline Alameda & 1.292 \\
\hline Aldeanueva & 105 \\
\hline Arcicollar & 412 \\
\hline "Arjezi" y Layos & 550 \\
\hline $\begin{array}{l}\text { Bailía de Olmos, con Cedillo, } \\
\text { Humanes,y Villamiel }\end{array}$ & 12.775 \\
\hline Barcience y Rielves & 1.732 \\
\hline $\begin{array}{l}\text { Berjamuñoz ["Borjamanos"], } \\
\text { con Santa Catalina }\end{array}$ & 528 \\
\hline "Bursalabajo" & 165 \\
\hline Burujón & 1.320 \\
\hline $\begin{array}{l}\text { Camarenilla, Yunclillos, Alba- } \\
\text { lat, Azoberín [“Azeruoryn”] y } \\
\text { Borgelín }\end{array}$ & 2.145 \\
\hline Casas Albas & 462 \\
\hline Caudilla & 1.155 \\
\hline Cebolla & 1.914 \\
\hline Ciruelos & 1.254 \\
\hline Cobeja & 363 \\
\hline Cuerva & 5.742 \\
\hline Diezma & 330 \\
\hline Escalonilla & 990 \\
\hline Esquivias & 1.705 \\
\hline Fuensalida y Portillo & 8.965 \\
\hline
\end{tabular}

44. R. Izquierdo Benito (1990), doc. 48. 


\begin{tabular}{|c|c|}
\hline Unidad de reparto tributario & Cuantía (mrs.) \\
\hline Fontalaba ["Fuentealvar"] & 412 \\
\hline Fuentelcaño & 330 \\
\hline Gálvez & 3.630 \\
\hline Gerindote ["Grandote"] & 1.155 \\
\hline Guadamur & 1.980 \\
\hline $\begin{array}{l}\text { Argance, Algurilla, Villa- } \\
\text { mocén y Renales ["Harzes", } \\
\text { "Algochilla", "Villamizán" y } \\
\text { "Renales"] }\end{array}$ & 709 \\
\hline Azaña y Yeles & 1.980 \\
\hline Huecas & 396 \\
\hline Jumilla & 614 \\
\hline Las Chozas & 726 \\
\hline Lominchar & 1.518 \\
\hline $\begin{array}{l}\text { Madrid con su tierra, sin los } \\
\text { señoríos }\end{array}$ & 46.200 \\
\hline Magán & 2.310 \\
\hline Malpica & 396 \\
\hline Manzaneque & 1.320 \\
\hline Marjaliza & 2.475 \\
\hline Mazarambroz & 3.300 \\
\hline Mazaraveda & 105 \\
\hline Mocejón & 2.310 \\
\hline $\begin{array}{l}\text { Montalbán y su tierra con Me- } \\
\text { nasalbas }\end{array}$ & 7.735 \\
\hline Móstoles y Lucero & 7.700 \\
\hline Nambroca & 594 \\
\hline Noves & 3.300 \\
\hline Nuez & 770 \\
\hline Olías y Vargas & 1.320 \\
\hline Orgaz & 6.600 \\
\hline Pantoja & 825 \\
\hline Parla & 3.300 \\
\hline $\begin{array}{l}\text { Pexinas de la Sagra, Yuncler, } \\
\text { Tozaneque y Adamuz }\end{array}$ & 2.887 \\
\hline
\end{tabular}




\begin{tabular}{|l|r|}
\hline Unidad de reparto tributario & \multicolumn{1}{|c|}{ Cuantía (mrs.) } \\
\hline $\begin{array}{l}\text { Pexinas de la Sisla, Santa Ma- } \\
\text { ría de Pexinas, Casasbuenas y } \\
\text { Alamedilla [“Almudilla] }\end{array}$ & 742 \\
\hline Peromoro y Majazul & 1.914 \\
\hline Pinto & 7.700 \\
\hline Polvoranca & 1.980 \\
\hline Pulgar & 2.640 \\
\hline Regachuelo & 858 \\
\hline Rodillas & 528 \\
\hline "Salva", Burguillos y Cobisa & 330 \\
\hline $\begin{array}{l}\text { Sonseca, Arisgotas y Casar- } \\
\text { gordo }\end{array}$ & 8.250 \\
\hline Torre de Esteban Hambrán & 4.950 \\
\hline Torrejón de Velasco & 3.135 \\
\hline $\begin{array}{l}\text { Torrijos, "Alcannio" y Fuen- } \\
\text { telmadero }\end{array}$ & 10.725 \\
\hline Totanes & 2.161 \\
\hline Vicaría de la Puebla de Alco- \\
cer con Siruela & 30.800 \\
\hline Villaminaya & $\mathbf{2 5 0 . 5 8 1}$ \\
\hline Villaseca & 660 \\
\hline Yébenes con San Andrés & 1.485 \\
\hline TOTAL & 9.042 \\
\hline
\end{tabular}


No conservamos nuevos repartimientos de "pedido" para el ámbito del arzobispado de Toledo hasta 1442, momento a partir del cual aparecen entre los papeles conservados en el Archivo General de Simancas pliegos con los repartos de la carga llevados a cabo por los contadores y oficiales regios para las distintas circunscripciones de Castilla en 1442, 1450, 1455, 1462 y 1473$1474^{45}$. Se trata, en este sentido, de una documentación de enorme interés, especialmente a nivel toponímico, ya que incluye los primeros nomenclátores completos de localidades procedentes de la documentación contable regia, gracias a los cuales es posible analizar de forma somera la distribución relativa de la carga tributaria realizada, según veremos, a comienzos del siglo $\mathrm{XV}$, quizás en función de parámetros como el reparto de la población pechera y su riqueza ${ }^{46}$.

No obstante, es necesario realizar con carácter previo algunas puntualizaciones referentes a la datación de estos repartimientos simanquinos, pues la ausencia de fecha en la mayor parte de esta documentación ha llevado a algunos errores de inventario. Por ejemplo, el "pedido" inventariado en 1457 consideramos que realmente es el distribuido en 1442. Hay dos indicios que nos llevan a considerar esta datación. En primer lugar, si comparamos las cifras totales del "pedido" incluidas en los repartos por localidades con las sumas totales a percibir en cada partido asentadas en el libro de "recepta" del "pedido" y "monedas" de los años 1442-1443, donde se consignaron todas las cuantías cobradas para la Real Hacienda por este concepto, observamos la correspondencia de ambas cantidades, con algunas variaciones poco significativas ${ }^{47}$. En segundo lugar, un documento dado el 20 de mayo de 1462 cifra en 110.030 mrs. el total repartido a Guadalajara y su tierra y lugares "encabezados" junto a 15 "monedas" en fecha indeterminada. Precisamente se trata de la cantidad distribuida en el reparto que el inventario adscribe a 1457, y realmente se debe datar, en nuestra opinión, en $1442^{48}$.

Por otra parte, algunos repartimientos del "pedido" de 1450 aparecen fechados, a tenor de los inventarios, en 1451. En este caso, la datación que consideramos correcta se ha establecido a partir de la comparación de los datos incluidos en un sumario del "pedido del Andalucía", correspondiente a

45. AGS, EMR, legs. 1, 16 y 17.

46. Es modélico el análisis de F. J. AguAdo GonzÁlez (1986), 465-480.

47. El libro de "recepta" en AGS, EMR, leg. 2, ff. 405-456. Los partidos correspondientes al arzobispado de Toledo en AGS, EMR, leg. 2, ff. 417v-422v.

48. AGS, EMR, leg. 14, f. 4. Conviene recordar que, efectivamente, en 1442 y 1443 se repartieron 15 "monedas" junto al "pedido". M. Á. LADERo QuesADA (2009b), Cuadro "Servicios de las Cortes castellanas en el siglo XV" [entre p. 220 y p. 221]. 
los $10.000 .000 \mathrm{mrs}$. otorgados por las Cortes para 1450 a percibir con otros $30.000 .000 \mathrm{mrs}$., con la suma total de los cupos por localidades incluidos en los repartimientos adscritos erróneamente a 1451. La equivalencia total entre ambas cifras solo se puede explicar fechando en 1450 estos repartimientos ${ }^{49}$. Finalmente, algunos de los repartimientos correspondientes a 1462 también han exigido de una rectificación de los datos de inventario. Por ejemplo, en una nota incluida en el reparto del arcedianazgo de Calatrava, el archivero escribió en 1833 que, según algunas notas, parecía ser el repartimiento de 1467, año en el cual no hubo concesión de "pedidos" y "monedas". No obstante, hay apuntes marginales en diversos pliegos que permiten fechar el reparto en 1462. Por ejemplo en el repartimiento del "pedido" de Castrojeriz se señala lo siguiente: "enbiaron dezir lo contadores mayores de las cuentas del rey nuestro señor a los contadores de las rentas del dicho señor rey por una su fe firmada de sus nombres fecha a cinco días de noviembre de 1462 años que tiene Ferrand Sánchez de Valladolid [...]". Igualmente, una nota marginal incluida en el repartimiento del "pedido" del obispado de Segovia señala lo siguiente: "en la carta del pedido para este obispado de Segovia d'este año de 1462 de que está su traslado al comienço d'este libro..." ${ }^{50}$ A todo ello se suma la coincidencia exacta de las cantidades totales por partido incluidas en los repartos con las incluidas en un sumario del "pedido" repartido con 16 "monedas", datado en $1462^{51}$.

Dejando a un lado la problemática establecida en torno a la datación de las fuentes, durante los años de la minoría de Juan II (1407-1419) se llevó a cabo una revisión de la base considerada a la hora de establecer los cupos asignados a cada localidad en los repartos del "pedido". A pesar de las carencias documentales, esta hipótesis se fundamenta en varios indicios. En primer lugar, los repartimientos conservados en las fuentes simanquinas a partir de 1442, aunque responden siempre a una distribución ad hoc de las sumas aprobadas para cada "pedido" concreto por las Cortes, fueron confeccionados aplicando un baremo proporcional -en función de la cantidad global repartida- a unos cupos preestablecidos en una fecha indeterminada, pero sin duda muy

49. Sumario del "pedido del Andaluzía" de los 10.000.000 mrs. otorgados por las Cortes en AGS, EMR, leg. 4-1, f. 1.

50. AGS, EMR, leg. 16, f. 147. Otra nota marginal: "diose carta del rey en la cibdad de Segovia XV días de febrero de 1463 años para que Gonzalo Rodríguez del Río, su recaudador mayor del pedido y XVI monedas del obispado de Segovia el año pasado de 1462 años...”.

51. Este sumario en AGS, EMR, leg. 17, f. 4. 
anterior a $1442^{52}$. Por ejemplo, entre el repartimiento de 1442 y el de 1450 se observa una relación proporcional de $4 \mathrm{mrs}$. de 1442 por cada maravedí de 1450, mientras que en los cupos repartidos entre 1450 y 1462 la proporción es aproximadamente de un maravedí de 1450 por cada 4,5 mrs. de 1462 . De esta forma el peso fiscal de cada "cabeza de pedido" - es decir, cada unidad de reparto tributario- se mantuvo en el tiempo, como veremos, aunque las cuantías distribuidas fueron adaptándose a la suma del servicio repartida como "pedido" en cada ocasión, habitualmente no especificada en los "otorgamientos"

En este sentido, hay datos procedentes de los repartimientos conservados desde 1442 que evidencian la configuración a comienzos del XV de lo que hemos denominado "plantilla base", es decir, el conjunto de unidades de reparto tributario reconocidas en cada circunscripción, repetido de manera formularia en cada nuevo repartimiento. Esto lo deducimos gracias a algunas menciones, completamente desfasadas, a los individuos que ejercían su jurisdicción señorial sobre un determinado territorio. Por ejemplo, en el repartimiento del "pedido" de 1442 correspondiente al arcedianazgo de Calatrava se menciona el lugar de Capilla como perteneciente al señorío de Diego López de Estúñiga ${ }^{54}$. Esta escueta referencia permitiría situar la confección de la "plantilla base" del repartimiento entre 1382, año en el cual Diego López de Estúñiga compró el mencionado señorío de Capilla, y 1417, fecha de la muerte del noble ${ }^{55}$. Si tenemos en cuenta que el reparto del "pedido" de 1399 se guió en el arzobispado de Toledo, tal y como hemos visto, por un patrón territorial que no tenía en cuenta el arcedianazgo como criterio de delimitación geográfica, según se considera en los repartos de 1442, 1450 y 1462, y que el siguiente "pedido" ya fue cobrado en 1407, la fecha de confección de la "plantilla base" queda acotada a un arco cronológico extendido entre 1407 y 1411, última fecha en la

52. Esta aplicación de un baremo proporcional ya fue advertida por el profesor M. Á. Ladero al analizar los repartimientos del "pedido" del área andaluza. M. Á. LADERo QueSADA (1969), 481-482.

53. Sobre la falta de concreción de la cuantía repartida como "pedido" en muchos servicios hay abundantes testimonios. Por ejemplo, en el transcurso de las Cortes de Valladolid de 1411, en las que se otorgó un servicio de 48.000 .000 mrs. pagadero en "monedas" y "pedido", los procuradores comunicaban a los regentes en relación a la cuantía repartida para cada uno de los conceptos que "con vuestro sano e vertuoso consejo e mandamiento e buena deliberación, nos pornemos luego asosegar e concertar en breue el numero e quantidat de cada cosa del dicho pedido e monedas quanto será, por las vias e maneras que entendiéremos que mejor e mas syn danno lo podrá pechar e cunplir el rregno, é vos rresponderemos luego en breue, por que non se ponga enello dilación nin otra tardanca alguna". Cortes (1866), vol. III, 6-7.

54. "Pedido" de 1442 en AGS, EMR, leg. 1, ff. 592-595.

55. M. J. Lop Otín (1990), 215-216. 
cual tenemos documentado el cobro de "pedido" antes de la muerte de Diego López de Estúñiga.

Otras referencias procedentes de los repartimientos conservados para los años iniciales del siglo XV en el reino de Murcia apoyan esta hipótesis, y permiten acotar la fecha de confección de la "plantilla base" a los años 14091411. Según los datos publicados por M. L. Martínez Carrillo el número de unidades tributarias que figuran en el reparto del "pedido" del espacio murciano sufrió alteraciones para los años 1397, 1399, 1407 y 1408. Sin embargo, los repartos de 1409, 1410, 1411 y 1419 comprenden el mismo número de localidades -la única excepción es Cartagena, incluida solo en el repartimiento de 1410-, a lo que se añaden las relaciones de proporcionalidad que se observan entre las sumas distribuidas a cada localidad conforme a baremo señalado en la Tabla 2, expresado en números índice tomando como año inicial 140956. En definitiva, esto solo puede significar que en 1409 se estableció un patrón de reparto territorial de la carga vigente en repartimientos futuros.

Tabla 2. Baremo proporcional entre las cuantías repartidas en forma de "pedido" en el reino de Murcia (1409-1419)

\begin{tabular}{|l|c|c|c|c|}
\hline Año & 1409 & 1410 & 1411 & 1419 \\
\hline Número índice & 100 & 87 & 127 & 64 \\
\hline
\end{tabular}

Es evidente que la confección de esta "plantilla base" utilizada para el cobro del "pedido" exigió a la Corona articular mecanismos de información que permitieran conocer a los oficiales hacendísticos la realidad demográfica de cada espacio fiscal que, pese a su enorme importancia, apenas han dejado rastro documental. El 20 de marzo de 1409 los regentes de Juan II remitían desde Valladolid al concejo de Murcia una provisión real en respuesta a las quejas planteadas por los concejos del reino ante los desequilibrios tributarios derivados de los cupos del "pedido" repartidos en 1407 y 1408. La misiva, que suponemos fue enviada a todo el territorio castellano, ordenaba "escrivir todos los fumos de todas las çibdades e villas e lugares de los dichos mis regnos porque sepan quantos son los vezinos e moradores que en cada una de las dichas çibdades e villas e lugares moran", a fin de evitar nuevos agravios. Para ello la Corona nombró en cada circunscripción -arzobispado, obispado, merindad,

56. Los datos concretos, por localidades, en M. L. Martínez Carrillo (1980), 47. 
arcedianazgo o sacada- agentes delegados con el encargo de escribir y contar los “fumos de los que ý moran e los vezinos por vezinos, e los moradores por moradores nonbrando por menudo quales son de cavallo e quales son de pie e quales son clerigos e biudas e huerfanos". Para facilitar su labor, y evitar fraudes y encubrimientos, estos pesquisidores reales contarían con la colaboración de los curas de las iglesias de cada collación y lugar, y de uno de los alcaldes locales -o en su defecto un "hombre bueno", allí donde no hubiese alcalde-, todos ellos puestos bajo el amparo y seguro real, y obligados a dar fe verdadera bajo juramento prestado ante el concejo y regimiento del lugar donde efectuaban la pesquisa ${ }^{57}$.

Sorprende la escasa atención que se ha prestado a esta pesquisa general ${ }^{58}$, que antecede en más de un siglo a la averiguación ordenada por Carlos $\mathrm{V}$ entre 1528 y 1536 y que, de haberse conservado, permitiría conocer en términos absolutos la realidad demográfica castellana a comienzos del siglo XV. De su proceso de ejecución y resultados apenas conservamos algunas menciones que, no obstante, permiten verificar su elaboración efectiva. Así, entre la documentación municipal de Sevilla de estos años se conserva un mandato del concejo dado el 22 de febrero de 1409 para que se pagasen, con cargo a las rentas "de propios", 3.000 mrs. al bachiller Juan Gómez, lugarteniente de Lope Ortiz de Zúñiga, alcalde mayor de la ciudad, por las escrituras de los "humos" de todos los vecinos y moradores de Sevilla, realizadas siguiendo el mandato regio ${ }^{59}$. Por otra parte, en el memorial que en torno a 1419 dirigieron a Juan II varios concejos de la merindad de Castilla la Vieja denunciando algunas actuaciones fraudulentas y abusos cometidos por los merinos mayores Pedro Fernández de Velasco, y su sucesor Juan de Velasco, leemos lo siguiente:

57. Para Cartagena, Murcia y las villas y lugares de su obispado y reino la Corona nombró como pesquisidores a Fernán González de Castro, escribano real, y Ortún Sánchez de Laredo. M.V.J. VilaPlANA GiSBERT (1993), doc. CVI, 187-189.

58. Únicamente se hace eco de ella J. D. GonZÁLez ArCE (2010), 21-22.

59. Archivo Municipal de Sevilla, Mayordomazgo XV. F. Collantes de Terán Delorme (1972), 276. S. GonzÁLEZ Sánchez (2010), 2191. Aunque la fecha del mandato de pago dado por el concejo de Sevilla (22 de febrero de 1409) es un mes anterior a la fecha de envío a Murcia de la provisión real ordenando la realización de la pesquisa (20 de marzo de 1409), ello no implica que no se hubiera podido remitir en fecha anterior una orden regia para la realización de la pesquisa en Sevilla. 
Iten quando la vuestra merçed con acuerdo de los señores reyna vuestra madre e rey de Aragón vuestro tio enbió a aquella tierra pesquisidores que sopiesen todos los fumos d'ella e los derechos que alla a vuestra merçed pertenesçían, el dicho Juan de Velasco con poderío del dicho ofiçio [de merino de la merindad de Castilla Vieja] puso muy grand miedo e temor a los conçejos e moradores en aquella tierra e les enbio mandar e mandó que dixiesen e jurasen honde ouiese veynte fumos que non auia mas de seys o siete e asy en todos los lugares [...]. E esto sennor fizo e mandó fazer el dicho Juan de Velasco por vfrandar [sic] la vuestra sennoria de sus derechos e sojudgar a los dichos logares ${ }^{60}$.

Desconocemos si la alusión a estos pesquisidores enviados por Catalina de Lancáster y el infante don Fernando ${ }^{61}$, regentes de Juan II, hay que entenderla únicamente en el marco territorial específico al cual se refiere el documento, o por el contrario debemos relacionarla -tal y como sospechamos-con la pesquisa ordenada con carácter general para toda Castilla con el objeto de llevar a cabo el reparto del "pedido" conforme a los "humos" contabilizados en cada población ${ }^{62}$. Sea como fuere, lo cierto es que las quejas por la falta de actualización de los cupos asignados en forma de "pedido" arreciaron en las reuniones de Cortes celebradas durante el reinado efectivo de Juan II $^{63}$. Así se desprende de la reclamación planteada al monarca por los procuradores reunidos en las Cortes de Burgos de 1430 para que rectificase los repartimientos del "pedido", de manera que cada pueblo contribuyese "segunt oy está poblado", pues...

...al tienpo que se escriuieron por mi mandado los fumos délas mis cibdades e villas e lugares délos mis rregnos e sennorios, se rrepartieron los pechos de cada cibdat e villa e lugar, segunt que eran los dichos fumos, e siguiéndose la dicha

60. A. Moreno Ollero (1994), 133-134. O. V. Pereyra Alza (2014), 211.

61. La titulación del infante don Fernando como rey de Aragón no afecta a la datación de la pesquisa, habida cuenta de que el memorial fue redactado en 1419, es decir, tres años después del fallecimiento de don Fernando, y lo normal sería referirse a él como rey de Aragón -lo era desde su proclamación en 1412- y no como infante, que es el título que ostentaba en 1409.

62. Llama la atención la falta de documentación para otros espacios, habida cuenta del enorme esfuerzo que tuvo que representar el envío de pesquisidores a todos los territorios del reino, y la propia elaboración de padrones por "humos". No obstante, para el establecimiento de la contribución de la Hermandad en 1478 también se llevó a cabo una pesquisa general en toda Castilla, que tampoco ha dejado rastro documental, al menos similar al que conocemos para la gran averiguación llevada a cabo entre 1528 y 1536 por Carlos $\mathrm{V}$, solicitada por las Cortes en 1525 . Ver a este respecto el estudio de J.M. CARRETERO ZAMORA (2008).

63. Los procuradores recordaban en las Cortes de Toledo de 1436 cómo "les fueron echados los dichos pedidos a rrespecto del anno que fueron escriptos los dichos fumos". Cortes (1866), vol. III, 267. 
ordenanca, que se fazen avn oy dia los rrepartimientos délos pedidos e tributos délos mis rregnos; e que era cierto e manifiesto que muchos délos dichos pueblos que son acrescentados e multiplicados enla pobladon dellos, e otros muchos se menoscabaron e despoblaron, e que agora los vnos han muy grant aliuio, e los otros muy grant danno e agrauio ${ }^{64}$.

Aunque Juan II se comprometió a corregir los repartos, las demandas cayeron en saco roto, tal y como evidencian las quejas en el mismo sentido planteadas durante las Cortes de Palencia de 1431 y de Zamora de 1432. En esta última reunión los procuradores propusieron al monarca utilizar en el proceso de revisión de los repartimientos las informaciones aportadas por los tesoreros y recaudadores, buenos conocedores de la realidad demográfica sobre la cual actuaba el fisco, así como por "otras muchas personas", a fin de evitar nuevas dilaciones en la resolución de los agravios, quizás derivadas de las dificultades materiales que implicaba la realización de un nuevo recuento de "humos". Juan II respondió comisionando al adelantado Pedro Manrique y a los contadores mayores para que determinasen el modo de proceder en este asunto $^{65}$, aunque, en las Cortes reunidas en Madrid en 1433, los representantes urbanos denunciaban el incumplimiento del acuerdo alcanzado, pues "non se ha fecho en ello cosa alguna". Nuevamente el monarca se comprometió a solucionar los agravios, ordenando a la comisión formada por el adelantado y los contadores mayores la máxima diligencia a fin de que el proceso de revisión concluyese antes del fin de la paga del "pedido" y "monedas" aprobado por las Cortes para ese año ${ }^{66}$.

Todavía las Cortes de Madrid de 1435 volvieron a recordar a Juan II sus compromisos previos, una vez más incumplidos. Ante la ineficiencia del monarca y de la comisión nombrada, esta vez los procuradores fueron más lejos, y no solo solicitaron que se mandase "escriuir todos los fumos de las cibdades e villas e logares délos vuestros rregnos e sennorios con muy grand diligencia", sino también quedar a cargo del proceso de recuento y de los gastos económicos que pudiera ocasionar. Como en ocasiones anteriores, el rey aceptó la propuesta de las Cortes, pero mostró sus reticencias a dotar de nuevos poderes y atribuciones a los representantes urbanos en un asunto tan sensible, que implicaba sumar al control sobre los mecanismos de tributación directa que ya ejercían los concejos, la renuncia de la Corona a establecer la

64. Cortes (1866), vol. III, 90-91.

65. Cortes (1866), vol. III, 102 y 136-137.

66. Cortes (1866), vol. III, 165. 
base que permitiría establecer los cupos distribuidos a cada unidad de reparto tributario, como venía sucediendo hasta el momento. Por ello, antes de adoptar cualquier decisión al respecto, Juan II instó a los procuradores a declarar la "orden e via" por la cual se realizaría el recuento, y las personas a las "que entendierdes que cunple" $"$.

\section{MECANISMOS DE REAJUSTE EN EL REPARTO DE LAS CARGAS: "IGUALAS" Y DESCUENTOS}

Las medidas solicitadas en 1435 nunca alcanzaron cumplimiento efectivo. La falta de voluntad del rey en la puesta en marcha de una pesquisa general llevó a las Cortes reunidas en Toledo en 1436 a articular una nueva estrategia de revisión de los cupos, sin renunciar a la averiguación de "humos" que formaba parte del programa de máximos de los procuradores ${ }^{68}$. En este sentido, la solución para actualizar las cuantías que no se ajustasen a los parámetros demográficos que debían regir la presión fiscal relativa, ya no partiría necesariamente del ajuste del cupo al número de pecheros, sino del establecimiento de "igualas" o acuerdos entre concejos. El procedimiento ya aparece mencionado en las Cortes de Burgos de 1430, cuando los procuradores solicitaron para paliar la despoblación que sufría la villa de Castro Urdiales, como consecuencia de las mortandades, guerras y los dos incendios que había sufrido en el pasado, una reducción o "quita" de su "cabeza de pedido", pues "non tienen alderredor villa nin lugar con quien se ygualase e rrepartiese el dicho pedido", habida cuenta de la cercanía del señorío de Vizcaya, exento del pago ${ }^{69}$. Hay que tener presente que la reducción del cupo asignado era un mecanismo de limitación de los desequilibrios tributarios al que se recurría excepcionalmente ante la imposibilidad manifiesta de un concejo para afrontar sus obligaciones tributarias. Por ejemplo, en relación al ámbito del arzobispado de Toledo,

67. "ca los procuradores délas vuestras cibdades e villas que aqui estamos con la vuestra sennoria, nos ofrecemos por vuestro seruicio e bien e pro común de todos los vuestros rregnos de tomar cargo dellos e de dar en ello tal orden e via para se fazer qual a vuestro seruigio cunpla, e eso mesmo dar rremedio para la costa que en ello se fiziere, dando a nos otros el cargo délo escriuir e fazer". Cortes (1866), vol. III, 224-225.

68. Las Cortes pidieron que las personas encargadas de realizar el recuento fuesen de la plena confianza del rey, aunque se les exigiría que prestaran juramento. Por otra parte, los "grandes" y caballeros del reino debían jurar "que por ellos nin otro por ellos nin por su mandado non farán nin consentirán fazer encubierta alguna enel escreuir délos dichos humos". Cortes (1866), vol. III, 268-269.

69. Cortes (1866), vol. III, 91. 
sabemos que el 10 de julio de 1442 Juan II ordenaba mediante albalá a sus contadores mayores descontar la mitad del "pedido" repartido a la villa de Escalona y su término, que quedó fijado en $25.855 \mathrm{mrs}$., ya que la villa no alcanzaba los 450 pecheros $^{70}$.

Más allá de estas quitas y descuentos, la petición referida a Castro Urdiales tiene interés por cuanto confirma que el procedimiento de la "iguala" ya se encontraba plenamente operativo en 1430, aunque hasta 1436 los procuradores no solicitaron al rey su extensión con carácter general a todas aquellas poblaciones agraviadas, tal y como se venía aplicando en algunos territorios señoriales ${ }^{71}$. Así, frente a las quitas y suspensiones aprobadas por la Corona, la "iguala" ofrecía una mayor operatividad en tanto no suponía una merma de recursos para la Real Hacienda. Como recuerda todavía el Libro de Hacienda de 1503, el mecanismo pasaba por solicitar al rey su consentimiento para que los cupos conjuntos de dos o más concejos se redistribuyesen de forma más equitativa conforme a su potencial demográfico ${ }^{72}$. La solución, a la que se recurrió con cierta frecuencia -tanta como para que los oficiales regios considerasen la elaboración de un formulario de aprobación de la "iguala"73 -, hay que enmarcarla en una dinámica caracterizada por la transmutación de un tributo que en origen debía ser personal, en una carga vinculada al territorio conforme a criterios que terminaron quedando disociados de parámetros demográficos, algo que en principio no ocurría con las "monedas". En este último caso, el régimen de arrendamiento "por mayor", y posteriormente "por menudo" -es decir, por localidades- por el cual se gestionaba esta parte de los servicios no permitía habitualmente el reparto de cupos fijos a cada territorio definidos en función de criterios proporcionales basados en repartimientos desfasados en razón de su antigüedad. En definitiva, el cobro del "pedido" dotaba de continuidad los principios del "encabezamiento" que tantas quejas habían provoca-

70. A. Malalana Ureña (2002), 176.

71. Los procuradores recordaban cómo cuando "en los logares délos sennorios do sienten el tal agrauio les es dada eguala con otros logares", de manear que pedían "que las dichas vuestras cibdades e villas e logares e déla dicha sennora Reyna vuestra muger non sean de menor condición, e que cada e quando por ellos fuere demandada yguala con otras cibdádes e villas e logares asy de rrealengos commo de sennorios, que mande quelessea fecha la dicha yguala". Cortes (1866), vol. III, 267-268.

72. “[...] en tienpo que avía repartimiento de pedido e monedas, quando se hallava un logar agraviado demandavan yguala del pedido con el logar e logares que querían, e fazíanse. E en lo de las monedas, no avía agravio porque se pagava por vezinos e por cabeças". J. M. Carretero Zamora y D. Alonso García (2003), 75.

73. Esta afirmación se deriva de la comparación de las cartas aprobando "igualas" dadas en 1442 y 1462. AGS, EMR, leg. 2, ff. 550-551; leg. 10, f. 77. 
do desde fines del siglo XIII y comienzos del XIV, tanto a nivel local ${ }^{74}$ como en el transcurso de las reuniones de Cortes ${ }^{75}$.

En lo que atañe al área toledana, tenemos documentadas algunas peticiones de redistribución mediante "iguala" del cupo asignado como "pedido". El 16 de enero de 1443 Juan II se dirigía a Fernán González de la Fuente, recaudador mayor del "pedido" del arcedianazgo toledano de 1440, tras la demanda presentada por el concejo de Alameda [de la Sagra], lugar del cabildo y deán de Toledo, en la cual se denunciaba el agravio que dicha localidad sufría en el repartimiento del "pedido" mandado satisfacer aquel año, especialmente si se comparaba la carga repartida a Alameda (1.605 mrs.) con la distribuida al vecino concejo de Borox, lugar de la orden de Calatrava (2.410 mrs.). Aunque el documento no lo expresa, es probable que la queja tuviese su origen -como tantas otras- en problemas asociados a la movilidad de población pechera desde Alameda a Borox favorecida por la existencia de una menor presión fiscal en la segunda localidad lo que, a su vez, redundaba en perjuicio de la primera que, además de pagar proporcionalmente más, veía cómo el descenso de su población empobrecía a sus vecinos pecheros, obligados a satisfacer una cuantía cada vez mayor ${ }^{76}$.

La solución al problema pasaba, a juicio del concejo de Alameda, por el reparto de los $4.015 \mathrm{mrs}$. a que ascendía la carga conjunta de ambas loca-

74. Por ejemplo, el 1 de enero de 1310 Fernando IV ordenaba rebajar de 4.000 a $3.000 \mathrm{mrs}$. el encabezamiento de los servicios de la villa de Illescas atendiendo a la súplica que le había manifestado el deán y cabildo de Toledo, pues los vecinos de dicha localidad "eran pobres e que el logar se astragava por razon de la grant cabeça que tenien en los servicios". A. Benavides (1860), vol. 2, doc. CDXCI.

75. M. Á. Ladero Quesada (2011), 242-243.

76. El mismo tipo de queja, con carácter genérico, figura en el cuaderno de Cortes de 1436. "Otrosy muy poderoso sennor, asy por los muchos pechos con que vuestros rregnos vos han seruido e siruen de cada dia para prosecución délas guerras que vuestra mercet ha ávido e ha, e por que enlas vuestras cibdádes e villas e logares non hay tanta gente commo avia al tienpo que vuestra mercet mandó escreuir los humos de vuestros rregnos, commo eso mesmopor las pestilencias que han rrecrescido después acá, e por se auer y do de algunas cibdádes e villas e logares vuestros, algunos logares de sennorio e avn fuera de vuestros rregnos las tales cibdádes villas e logares vuestros e déla sennora Reyna vuestra muger han seydó e son agraviados, especial mente enlas cabecas de vuestros pedidos, que les fueron echados los dichos pedidos a rrespecto del anno que fueron escriptos los dichos famos enlo qual han rrescebido e rresciben muy grant agrauio, de guisa quelo non pueden conplir en ninguna manera; e que en algunas délas tales cibdádes e villas do cabia al pechero enel dicho vuestro pedido ciento e cinquenta mrs. poco mas o menos, caben les agora por mengua déla gente que enellas non ay quinientos e ochocientos e mill mrs., lo qual es causa de se despoblar vuestras cibdádes é villas e logares e grant cargo de conciencia quela suma que avian de pagar los muchos que morauan enlas dichas cibdádes e villas e logares quando se escriuieron los dichos humos, lo pagan agora los pocos que enellas quedaron por las cosas suso dichas". Cortes (1866), vol. III, 267-268. 
lidades "segund los vezinos que ay en cada uno de los dichos conçejos e las faziendas que tyenen", ante lo cual el rey, con objeto de evitar una demora en el pago, ordenó a ambos concejos la entrega de la cantidad repartida inicialmente a cada uno. A continuación, y una vez satisfecho el pago, el recaudador mayor Fernán González de la Fuente, junto a dos "omes buenos de buena fama" nombrados por cada uno de los dos concejos, se encargaría de confeccionar en un plazo de 60 días un nuevo repartimiento de los 4.015 mrs. que ambas localidades tenían asignados, según lo que cada una "mereçiese segund el lugar que fuere, e los vezinos que en él moraren, e las faziendas que cada uno toviere, en manera que uno non sea más agraviado que otro, non menguando ninguno nin algunos de los dichos quatro mill e quinze mrs." 77 . De esta forma, el rey evitaba cualquier perjuicio en sus ingresos autorizando una solución de consenso que permitía establecer nuevas cuotas tributarias con las que se pretendía limitar el impacto demográfico y económico de los desequilibrios fiscales.

El ejemplo de Alameda, que no es un caso aislado, resulta sintomático de una situación estructural que evidencia el control sobre la presión fiscal ejercido desde la Corona, pero también su incapacidad -o falta de voluntad-para ajustarla a parámetros demográficos conocidos a partir de pesquisas ordenadas ex profeso para el cobro de cada "pedido". En este sentido, la monarquía únicamente se limitó a "parchear" algunos de los repartos tras las denuncias presentadas por los concejos agraviados, que probablemente establecieron en torno a la fiscalidad directa regia uno de los puntos centrales de sus reivindicaciones, tal y como se constata a través de otros ejemplos tomados de los repartimientos del "pedido" de las décadas de 1450 y 1460.

Una nota marginal incluida en el repartimiento del "pedido" del arcedianazgo de Toledo de 1450 refiere la provisión de un albalá por Juan II para que el concejo de Casasbuenas no fuese acrecentado en su "cabeça de pedido" con objeto de facilitar su poblamiento con más vecinos, al tiempo que se prohibía su "iguala" con otro concejo, pues ello podría resultar lesivo al objetivo planteado $^{78}$. Más adelante, el 9 de diciembre de 1463 Enrique IV se dirigía a los

77. AGS, EMR, leg. 2, ff. 550-551. Al final del documento se señala la provisión de otra carta de contenido semejante para cierto concejo, no especificado, situado en la merindad de Monzón, en conflicto con el concejo de Santillana.

78. "Este conçejo de Casas Buenas tiene alvalá del rey que non se le acresçiente la cabeça del pedido en razón que se pueble de más vezinos, salvo al respecto que agora está encabeçada, nin se le dé yguala con otro conçejo alguno, del qual alvalá está el traslado en el libro del salvado de mrs. al comienço d'este arçedianadgo de Toledo". AGS, EMR, leg. 1, ff. 677-687. 
recaudadores mayores del "pedido" y 16 "monedas" repartidas en 1462 en el mismo arcedianazgo de Toledo, a la sazón Luis de Toledo -hijo de Juan Álvarez Zapata- y García Sánchez de Ciudad, ante la reclamación expresada por el concejo de Esquivias. De nuevo el mecanismo de la "iguala" fue la solución al desequilibrio tributario propuesta por el concejo agraviado, que planteó el reparto de los 18.134 mrs. que correspondía abonar en total en 1462 a las localidades de Esquivias, Yeles, Alameda, Cobeja y Azaña [hoy Numancia de la Sagra ${ }^{79}$-todos ellos lugares del cabildo de Toledo-, "ygualmente segund los vezinos que ay en cada uno de los dichos conçejos e las faziendas que tienen". La demanda, una vez valorada por los contadores mayores del rey, fue aceptada en términos idénticos a los aprobados en la orden dada en 1443 a petición de Alameda: pago inicial de la carga por cada concejo, comisión de reparto formada por el recaudador con dos "hombres buenos" nombrados por cada concejo, e imposibilidad de reducir el total en concepto de "pedido"

Junto al procedimiento de la "iguala", que no introducía modificaciones reales en los repartimientos, sino tan solo en la distribución de la carga entre los núcleos a los cuales afectaba, las alteraciones jurisdiccionales también eran susceptibles de provocar cambios. No obstante, se trata de una situación poco generalizada y con un impacto mucho mayor, por lo que parece, en las cuentas presentadas por los recaudadores mayores de cada circunscripción, donde -a tenor de las escasísimas relaciones conservadas- en ocasiones se reflejaban las variaciones en las cuantías del "pedido" motivadas por la inclusión de algunas localidades junto a otras en sus respectivas "cabezas"81. En otros casos, los cambios en la titularidad jurisdiccional de una localidad, podían dar lugar a demandas de reajuste en los repartimientos, que además evidencian, tal y como hemos visto con las "igualas", la dependencia de la Corona de sus gestores tributarios -recaudadores, habitualmente- a la hora de recabar la información sobre la cual se sustentaba la toma de decisiones.

Por ejemplo, sabemos que el concejo de Guadalajara solicitó el descuento de la cantidad distribuida en concepto de "pedido" por el lugar de Valfermoso

79. Las cantidades que debía satisfacer cada concejo eran las siguientes: Esquivias: 6.457 mrs.; Yeles: 1.676 mrs.; Alameda: 3.611 mrs.; Cobeja: 2.790 mrs.; Azaña: 3.600 mrs.. En efecto, las cantidades coinciden exactamente con las incluidas en el repartimiento de 1462. AGS, EMR, leg. 16 f. 151.

80. AGS, EMR, leg. 10, f. 77.

81. Se conserva, por ejemplo, una cuenta del obispado de Sigüenza para el año 1462 donde, efectivamente se anotaron las discordancias entre las cantidades incluidas en los repartimientos elaborados en la Contaduría y la adscripción jurisdiccional de algunos enclaves a otras localidades. AGS, EH, leg. 1, f. 95. 
de las Sogas [de las Monjas], que había formado parte de su término y jurisdicción hasta su entrega como merced al infante Juan de Navarra. El problema radicaba en la exención de "pedido" que Valfermoso, incluido en los repartimientos junto a la ciudad de Guadalajara y su tierra, había disfrutado hasta este momento, de manera que su salida de la jurisdicción urbana debía estar acompañada, según defendía la ciudad, de una reducción de la cantidad que se le repartía a esta última. Para ello, Juan II ya había ordenado en un momento indeterminado a Luis González de Toledo obtener información relativa a la cantidad repartida a dicho lugar "por que aquello le fuese encabeçado e fuese descargado a la dicha çibdad e su tierra de la cabeça de pedido que tyene". Dicha pesquisa, no obstante, no llegó a efectuarse, de manera que Enrique IV, tras obtener nueva información del mismo Luis González, ordenaba el 20 de mayo de 1462 descontar de la "cabeça de pedido" de Guadalajara 9.069 mrs. de cada $119.030 \mathrm{mrs}$. - cantidad a la que ascendía el "pedido" repartido a la ciudad en 1442 - correspondientes a Valfermoso, al tiempo que mandaba que dicho lugar, en ese momento jurisdicción del marqués de Santillana Diego Hurtado de Mendoza, "de aquí adelante vaya nombrado por sy en las cartas de pedido" 82 .

Más allá de la problemática asociada a las "igualas" y descuentos, y de las leves modificaciones incorporadas en las "plantillas" utilizadas como base en los repartimientos, otro de los problemas recurrentes asociados al cobro efectivo de los "pedidos" -y también de las "monedas"- nacía de la consideración de muchos de los lugares incluidos en los repartimientos, bien como despoblados o "yermos", bien como lugares privilegiados, y por lo tanto exentos de contribuir. Dejando a un lado las consideraciones en torno a las exenciones tributarias $^{83}$, las cantidades de los "pedidos" y "monedas" correspondientes a estos lugares eran puestas habitualmente como descuento por los recaudadores $\mathrm{y}$ arrendadores mayores en las datas de sus oficios entregadas a los contadores mayores de cuentas ${ }^{84}$, lo cual no solucionaba en modo alguno las injusticias tributarias que de ello se seguían, especialmente el incremento de la presión fiscal sobre otros territorios que la ya comentada falta de revisión de la base utilizada para repartir los cupos podía llevar aparejada.

82. AGS, EMR, leg. 14, f. 4.

83. M. Á. LADERO QUESADA (2009b), 211-214.

84. Cuenta del "pedido" y "monedas" recaudado en el obispado de Sigüenza en 1469. AGS, EMR, leg. 15, f. 445. Cuenta del "pedido" y "monedas" de 1469 cobrado en el arcedianazgo de Talavera. AGS, EMR, leg. 15, f. 441. Cuenta del "pedido" y monedas del arcedianazgo de Toledo de 1469. AGS, EMR, leg. 15, f. 440. 
Por este motivo las Cortes solicitaron en distintos momentos actuaciones tendentes a limitar el impacto provocado por ambas situaciones, hasta que en 1462 los procuradores consiguieron que el rey aceptase enviar cartas, que serían pregonadas en las "cabezas" de cada circunscripción fiscal durante nueve días, ordenando que todos los concejos y personas que tuviesen privilegios de franqueza de "pedidos" y "monedas" sin asentar en los libros "de lo salvado" presentasen en cuarenta días ante los contadores mayores los títulos originales para su comprobación efectiva. Al mismo tiempo, y en relación con los lugares yermos puestos como descuento por los arrendadores y recaudadores, se solicitó la realización en cada partido de una pesquisa "de los logares que tyenen cabeça de pedido" -es decir, que tenían asignada de forma específica un cupo- "e se ponen por yermos" de cara a la realización de un ajuste de la presión fiscal conforme al número y calidad de sus pecheros ${ }^{85}$.

Como en otras ocasiones, tampoco la medida aprobada en las Cortes de 1462 alcanzó cumplimiento efectivo. Así lo evidencia la petición presentada por las autoridades de Toledo a los Reyes Católicos solicitando su intervención para acabar con los agravios que generaba el cobro del servicio en lugares "yermos e despoblados" de su tierra, muchos de los cuales eran "heredamientos" de "pan" o vino, y "yermos" de algunas iglesias, monasterios, caballeros, dueñas y otras personas de la ciudad, de su tierra y de "fuera parte". Al parecer, los recaudadores de los "pedidos" y "monedas" percibidos desde 1473 habían demandado a los propietarios de estos espacios el pago de la cantidad incluida en el repartimiento, a pesar de que las sumas de los lugares "yermos" que tenían "cabeça de pedido", según las leyes del reino, debían ser consumidas y descontadas de los libros de la Real Hacienda, algo que nunca ocurrió. En este sentido, aunque el razonamiento expresado por los recaudadores para solicitar el pago se basaba en el aprovechamiento que estas personas realizaban de los lugares despoblados -"paçen, e cortan e roçan en los dichos términos", leemos en el documento-, los afectados lo negaron y argumentaron su posición, como venía siendo habitual en este tipo de conflictos, en la despoblación del territorio provocada por el incremento de la presión fiscal.

Ante la disputa, los reyes ordenaban desde Madrid el 25 de marzo de 1477 a los gestores de los servicios cobrados desde 1473 cumplir la ley sobre "yermos" aprobada en las Cortes de 1462, y la realización de una pesquisa relativa a estos lugares despoblados. Una vez llevada a cabo esta averiguación, se procedería de la siguiente manera. En caso de hallarse en estos lugares 
un vecindario suficiente se ordenaba el mantenimiento del cupo de "pedido" asignado. Si el número de vecinos resultaba insuficiente para satisfacer el pago, la cuantía "que se menoscabare" sería repartida a los lugares más cercanos que estuviesen "más aliviados de pedidos", siempre y cuando fuesen del mismo partido fiscal, y semejantes en jurisdicción. Si por el contrario los lugares eran realmente "yermos", pero existía un aprovechamiento en forma de dehesa o ejido por parte de algún lugar o sujeto, este último sería el encargado de satisfacer la cantidad repartida en concepto de "pedido". Finalmente, en los lugares completamente "yermos" en los cuales no existía memoria de sus términos, el cupo del "pedido" se repartiría entre los restantes lugares del partido "segund que cada uno mejor lo puede pagar"

A pesar de la importancia de lugares francos y yermos en la mecánica establecida en torno a la recaudación del servicio, especialmente por la instrumentalización de ambas categorías a la hora de evadir la tributación, su incidencia cuantitativa era mucho menor que la ejercida por las "tomas" señoriales, que constituían la partida a descontar más sustanciosa y la que más impacto tenía, no solo a nivel cuantitativo, sino también como expresión de un régimen político en el cual la nobleza trataba de compartir con el monarca el control de la fiscalidad regia a partir de diferentes instrumentos legales ("cartas de fin e quito") o ilegales ("tomas") 87 . Así, mientras en 1455 el total descontado por "yermos" ascendía en todo el reino a $1.300 .000 \mathrm{mrs}$. (1,5\% del cargo total del servicio), los descuentos por los "pedidos" y "monedas" de las ciudades, villas y lugares privilegiados suponían 4.000.000 mrs. (4,6\% del cargo total del servicio). Escasa cantidad si se compara con los 34.000 .000 mrs. (39\% del total) puestos como descuento por los "pedidos" y "monedas" de los lugares de señorío durante el mismo bienio ${ }^{88}$.

Los datos conocidos para el caso del arzobispado de Toledo confirman estas apreciaciones generales. Así, las cuantías descontadas por "yermos" incluidas en la relación pormenorizada del descuento aceptado a los recaudadores de "pedidos" y "monedas" de 1455 y 1456 por los lugares yermos, privilegiados y de señorío "e de lo que les ocupan los señores además de lo que es librado a los dichos señores fasta fin de 1457", ascendieron únicamente

86. Archivo Municipal de Toledo, Archivo Secreto, Cajón 8, leg. 2, núm 4. Copia en AGS, Registro General del Sello, marzo de 1477, f. 160.

87. Sobre estos instrumentos, especialmente aplicados a la fiscalidad ordinaria durante el siglo XV, aunque también al cobro del servicio, ver P. ORTEGO Rico (2013c), 127-167 y la bibliografía allí recogida.

88. AGS, EMR, leg. 16, f. 8. 
a 1.000 mrs., consignados en el arcedianazgo de Guadalajara ${ }^{89}$, aunque en una relación de cuenta del "pedido" y "monedas" de Madrid de 1455 también se incluye el descuento de $12.000 \mathrm{mrs}$. en concepto de lugares "yermos" ${ }^{\text {" }}$. Por el contrario, los descuentos por cuantías no percibidas en los territorios señoriales ascendieron globalmente a la enorme suma de 5.078.000 mrs.

Tabla 3. Descuentos puestos por los recaudadores de los "pedidos" y "monedas" en el arzobispado de Toledo durante el bienio 1455-1456 ${ }^{91}$

\begin{tabular}{|l|r|r|r|}
\hline \multicolumn{1}{|c|}{ PARTIDO } & \multicolumn{1}{|c|}{ YERMOS } & PRIVILEGIADOS & \multicolumn{1}{c|}{ SEÑORÍOS } \\
\hline Guadalajara, arcedianazgo & 1.000 & 21.000 & 1.930 .000 \\
\hline Madrid, arcedianazgo & 0 & 0 & 870.000 \\
\hline Toledo, arcedianazgo & 0 & 0 & 300.000 \\
\hline Talavera, arcedianazgo & 0 & 0 & 250.000 \\
\hline Calatrava, arcedianazgo & 0 & 0 & 1.428 .000 \\
\hline Alcaraz, arcedianazgo & 0 & 0 & 300.000 \\
\hline TOTAL & 1.000 & 21.000 & 5.078 .000 \\
\hline
\end{tabular}

\section{CONCLUSIÓN}

Pese a las carencias y dificultades señaladas, los repartimientos del "pedido" regio, consolidado ya desde 1399 como parte fundamental de los servicios otorgados por las Cortes, constituyen una fuente valiosísima, aunque incompleta, para establecer hipótesis generales sobre la estructura general del poblamiento castellano. En este sentido, a pesar de los interrogantes que plantea la pesquisa o averiguación general de "humos" de 1409, que consideramos debe ser puesta en valor como antecedente de otras posteriores, y de la ausencia de carta regias de repartimiento de la carga en muchos archivos municipales para las décadas iniciales del siglo XV, la utilización como base analítica de repartimientos muy posteriores puede aportar nuevas claves siempre en relación al poblamiento y reparto demográfico vigente a inicios del siglo $\mathrm{XV}$, habida cuenta de que los cupos asignados a cada unidad tributaria en los re-

89. AGS, EMR, leg. 7, ff. 698-699.

90. AGS, EMR, leg. 5-1, f. 156.

91. AGS, EMR, leg. 7, ff. 698-699. 
partos conservados en el Archivo General de Simancas a partir de 1442 fueron calculados aplicando un baremo proporcional sobre la base de la pesquisa de "humos" llevada a cabo en $1409^{92}$. No obstante, es evidente que este tipo de análisis nada puede aportar en relación con el cálculo de cifras globales de pecheros, vecinos o habitantes, pues se desconoce la cuantía pagada "por cabeza" en cada caso, así como el porcentaje de exentos, aunque sí mantiene su operatividad para establecer magnitudes demográficas relativas en una época carente de cualquier otro tipo de información de carácter cuantitativo.

Por otra parte, la mecánica establecida a la hora de distribuir el "pedido", también permite valorar cuestiones de marcado carácter político, fundamentales si tenemos en cuenta que atañen a una de las principales fuentes de renta de la monarquía hasta 1477. Acaso una de las más destacadas sea el mantenimiento en manos de la Corona de importantes atribuciones fiscales en relación a la distribución de una parte fundamental de las sumas concedidas por las Cortes, cuyo reparto nunca fue delegado en los concejos ni en las instituciones que ejercían la "representación" política del reino, incapacitadas para fijar las cuantías globales a satisfacer en cada caso, dependientes únicamente de la voluntad del poder regio y de sus instituciones y oficiales hacendísticos. De ahí el impacto que a nivel político tenía la configuración de las bases cuantitativas sobre las cuales se asentaban los repartos, en torno a los cuales las Cortes libraron una particular lucha con el monarca, especialmente evidente en la década de 1430, ampliada posteriormente, ya a título particular, a los concejos agraviados. La pugna se saldó de forma aparentemente favorable a los intereses regios, a tenor de los mecanismos de corrección de los desequilibrios tributarios adoptados habitualmente ("igualas", distribución de los cupos asignados a los yermos), que no implicaban un menoscabo de las cuantías a percibir finalmente por parte de la Real Hacienda, aunque resulta obvio que la falta de ajuste de las sumas distribuidas en cada "cabeza de pedido" a su realidad demográfica pudo condicionar desajustes en la presión fiscal lesivos a los intereses de aquellos concejos que, por el motivo que fuese, perdían población, y por lo tanto posibilidades de afrontar en mejores condiciones sus obligaciones fiscales con la Corona.

92. Este procedimiento de análisis ya fue señalado para el estudio de la población del área andaluza de mediados del siglo XV. M. Á. LAdERo Quesada (1969), 480-482. No obstante, el peso demográfico que se deduce de los datos aportados por los repartimientos del "pedido" de 1476-1477 manejados por el autor debe retrotraerse en realidad a los años iniciales del siglo XV. 


\section{BIBLIOGRAFÍA}

Aguado González, Francisco Javier (1986), "Fuentes para el estudio de la geografía administrativa y distribución de la población en la corona de Castilla en la segunda mitad del siglo XV: las relaciones de pueblos para el cobro del pedido", Anuario de Estudios Medievales, 16, pp. 465-480.

Benavides, Antonio (1860), Memorias de D. Fernando IV de Castilla, Imprenta de José Rodríguez, Madrid, vol. 2.

Cañas Gálvez, Francisco de Paula (2012), Burocracia y cancillería en la corte de Juan II de Castilla (1406-1454). Estudio institucional y prosopográfico, Universidad, Salamanca.

CARretero Zamora, Juan Manuel (2008), La averiguación de la Corona de Castilla (1525-1540). Los pecheros y el dinero en la época de Carlos V, Junta de Castilla y León, Valladolid. 3 vols.

Carretero Zamora, Juan Manuel, Alonso García, David (2003), Hacienda y negocio financiero en tiempos de Isabel la Católica. El libro de hacienda de 1503, Editorial Complutense, Madrid.

Carriazo y Arroquia, Juan de Mata (ed.) (1982), Crónica de Juan II de Castilla, Real Academia de la Historia, Madrid.

Collantes de Terán Delorme, Francisco (1972), Inventario de los papeles del Mayordomazgo del siglo XV. Tomo 1 (1401-1416), Ayuntamiento de Sevilla- Delegación de Cultura, Sevilla.

Cortes de los antiguos reinos de León y de Castilla (1863), Real Academia de la Historia, Madrid, vol. 2.

Cortes de los antiguos reinos de León y de Castilla (1866), Real Academia de la Historia, Madrid, vol. 3.

García DíAz, Isabel (1989), "Fiscalidad real sobre Murcia a finales del Trescientos (1370-1390)", Hispania, 49/173, pp. 841-893.

GonzÁlez Arce, José Damián (2010), "Los precedentes de la fiscalidad extraordinaria de la monarquía hispana: los pedidos reales en la Castilla al sur del Tajo (siglo XIV y XV)", en A. Collantes de Terán SáncheZ (ed.), Fuentes para el estudio del negocio fiscal y financiero en los reinos hispánicos (siglos XIV-XVI), Instituto de Estudios Fiscales-Red Arca Comunis, Madrid, pp. 11-40.

GonZÁlez JimÉneZ, Manuel (1979), “Un cuaderno de 'pedido' de Juan I”, en Homenaje al Dr. Muro Orejón, Universidad, Sevilla, vol. I, pp. 33-43.

GonzÁlez SÁnchez, Santiago (2010), La Corona de Castilla: vida política (1406-1420), acontecimientos, tendencias y estructuras. Tesis doctoral 
inédita. Departamento de Historia Medieval, Universidad Complutense de Madrid.

Hernández, Francisco Javier (1993), Las rentas del rey. Sociedad y fisco en el reino castellano del siglo XIII. Volumen II. Estadística, mapas e índices, Fundación Ramón Areces, Madrid.

IzQuierdo Benito, Ricardo (1990), Privilegios reales otorgados a Toledo durante la Edad Media (1101-1494), Instituto Provincial de Investigaciones y Estudios Toledanos-Diputación Provincial, Toledo.

Ladero Quesada, Miguel Ángel (1969), "La población de Andalucía en el siglo XV. Nota provisional", Anuario de Historia Económica y Social, 2, pp. 479-497.

- (1986), "Las alcabalas de Sevilla y su reino en 1399", en Estudios en Homenaje a Don Claudio Sánchez Albornoz en sus 90 años, Instituto de Historia de España, Buenos Aires, vol. 4, pp. 195-214.

- (1992), "Los primeros pasos de la alcabala castellana, de Alfonso X a Pedro I", Anuario de Estudios Medievales, 22, pp. 785-801.

- (2009a), "La Hacienda Real de Castilla (1369-1429)", en ÍDEM, La Hacienda Real de Castilla. Estudios y documentos (1369-1504), Real Academia de la Historia, Madrid, pp. 401-483. Reed. LADERo QuesAdA, Miguel Ángel (1988), "Cortes de Castilla y León y fiscalidad regia (1369-1429)", en Las Cortes de Castilla y León en la Edad Media, Valladolid, Cortes de Castilla y León, vol. 1, pp. 289-373.

- (2009b), "La Hacienda Real de Castilla en el siglo XV", en ÍDEM, La Hacienda Real de Castilla. Estudios y documentos (1369-1504), Real Academia de la Historia, Madrid, pp. 1-399. Reed. Ladero QuesadA, Miguel Ángel (1973), La Hacienda Real de Castilla en el siglo XV. Universidad, La Laguna.

- (2011), Fiscalidad y poder real en Castilla (1252-1369), Real Academia de la Historia, Madrid ( $2^{\mathrm{a}}$ ed.)

Lop OTín, María José (1990), "Un ejemplo del proceso señorializador extremeño: el señorío de Capilla (siglos XIII-XVI)", En la España Medieval, 13, pp. 207-232.

Luis López, Carmelo y Del Ser QuiJano, Gregorio (1990), Documentación medieval del Asocio de la Extinguida Universidad y Tierra de Avila. Tomo 1, 1181-1450, Institución Gran Duque de Alba, Ávila.

Malalana Ureña, Antonio (2002), La villa de Escalona y su tierra a finales de la Edad Media, Fundación Felipe Sánchez Cabezudo, Madrid. 
Martínez Carrillo, María de los Llanos (1980), "Servicios castellanos y política municipal: aspectos fiscales de la reforma concejil murciana de 1399", Miscelánea Medieval Murciana, 5, pp. 35-82.

- (1987-1988), "Servicios castellanos y política municipal (1420-1450)", Miscelánea Medieval Murciana, 14, pp. 273-332.

Menjot, Denis (1978), "L'incidence sociale de la fiscalité directe des Trastamares de Castille au XIVe siècle", Historia. Instituciones. Documentos, 5, pp. 1-43.

- (1979), "La fiscalité royale directe en Castille sous les premiers Trastamare. Remarques sur l'évolution d'une pratique financière dans un cadre urbain (1374-début du XVe siècle)", en Actes du 102e. Congrès National des Sociétés Savantes (Limoges, 1977) section de Philologie et d'Histoire jusqu'à 1610. Vol.1, Etudes sur la fiscalité au Moyen Age, Secretariat d'Etat aux Universités-Comité des Travaux Historiques et Scientifiques, Paris, p. 91-108.

- (1997), "Les villes castillanes et la fiscalité royale. Le cas de Murcie sous les Trastamara (1369-1474)", en Actes Col-loqui Corona, Municipis i Fiscalitat a la Baixa Edat Mitjana, Institut d'Estudis Ilerdencs, Lleida, pp. 125-144.

- (1999), "La fiscalité directe dans les systèmes financers des villes castillanes", en Menjot, Denis, y Sanchez Martínez, Manuel (coords.), La fiscalité des villes au Moyen Âge (Occident méditerranéen). 2. Les systèmes fiscaux, Privat, Toulouse, pp. 223-257.

Millares Carlo, Agustín y Varela Hervías, Eulogio (1932), Documentos del Archivo General de la Villa de Madrid. Segunda serie. Tomo I, Artes Gráficas Municipales, Madrid.

Mitre FernándeZ, Emilio (1980), "Mecanismos institucionales y poder real en la Castilla de Enrique III", En la España Medieval, 1, pp. 317-328.

- (1999), "Las Cortes de Castilla y las relaciones exteriores en la Baja Edad Media: el modelo de Enrique III”, Hispania, vol. 59, núm. 201, pp. 115148.

MolÉNAT, Jean-Pierre (1997), Campagnes et monts de Tolède du XIIe au XVe siècle, Casa de Velázquez, Madrid.

Moreno Ollero, Antonio (1994), "Gobierno y actuación de los Velasco en la merindad de Castilla Vieja a fines de la Edad Media", Estudios de Historia y de Arqueología medievales, 10, pp. 121-137. 
Nieto SoRia, José Manuel (2010), "El consenso como representación en la monarquía de la Castilla Trastámara: contextos y prácticas", Edad Media: revista de Historia, 11, pp. 37-62.

Olivera Serrano, César (1991), "Empréstitos de la corona de Castilla bajo la dinastía Trastámara", Hispania, 51, pp. 317-327.

- (2004), "El pedido de 1455 en el Reino de Galicia", Cuadernos de Estudios Gallegos, vol. 51, núm. 117, pp. 363-374.

Ortego Rico, Pablo (2013a), "Guerra y paz como fundamentos legitimadores de la exacción fiscal en Castilla: teoría y práctica (siglos XIII-XV)", en Ana Arranz Guzmán, María del Pilar RÁbade Obradó y Óscar VillaRROEL GonzÁLez (coords.), Guerra y paz en la Edad Media, Sílex Ediciones, Madrid, pp. 67-107.

- (2013b), Hacienda, poder real y sociedad en Toledo y su reino (siglo $X V$-principios del XVI). Tesis doctoral inédita. Departamento de Historia Medieval, Universidad Complutense de Madrid.

- (2013c), "Monarquía, nobleza y pacto fiscal: lógicas contractuales y estrategias de consenso en torno al sistema hacendístico castellano (14291480)", en José Manuel Nieto Soria y Óscar Villarroel González (coords.), Pacto y consenso en la cultura política peninsular. Siglos XI al $X V$, Sílex Ediciones, Madrid, pp. 127-167.

- (2015), "La contribución de la Hermandad en Castilla la Nueva: modelos tributarios y poderes concejiles", Chronica nova, 41, pp. 275-323.

Pereyra Alza, Osvaldo Víctor (2014), El Señorio de los Condestables de Castilla en el Norte de España. Dominio, Patronazgo y Comunidades. Tesis doctoral inédita. Universidad de Cantabria.

RodríGUeZ SARRIA, Julieta (2012), “¿Cobrar para el rey?. Los pedidos regios: procedimientos y agentes de la recaudación en la Sevilla del siglo XV", en Ángel Galán SÁnchez y Ernesto García Fernández (coords.), En busca de Zaqueo: los recaudadores de impuestos en las épocas medieval y moderna, Instituto de Estudios Fiscales, Madrid, pp. 79-98.

Rodríguez Sarria, Julieta, Triano Milán, José Manuel (2015), “Algunas consideraciones en torno a la concesión, recaudación y gasto del pedido regio en Sevilla y su tierra en 1454", En la España Medieval, 38, pp. 329-352.

Romero Martínez, Adelina (1998), Los papeles del fisco. Estudio diplomático de la documentación fiscal castellana bajomedieval, Grupo Editorial Universitario, Granada. 
- (1999), Fisco y recaudación: impuestos directos y sistemas de cobro en la Castilla Medieval, Grupo Editorial Universitario, Granada.

Romero Romero, Francisco José (1997), Sevilla y los pedidos de cortes en el siglo $X V$, Ayuntamiento. Área de Cultura, Sevilla.

Sánchez Albornoz, Claudio (1965), "Notas para el estudio del 'petitum", en ÍDEM (ed.), Estudios sobre las instituciones medievales españolas, Universidad Nacional Autónoma, México, pp. 483-519.

Ser Quijano, Gregorio del (1998), Documentación medieval en archivos municipales abulenses, Institución Gran Duque de Alba, Ávila.

Serrano, Luciano (1907), Fuentes para la historia de Castilla por los PP. Benedictinos de Silos. Vol. 2. Cartulario del Infantado de Covarrubias, Cuesta Editor, Valladolid.

Triano Milán, José Manuel (2013), "El arzobispado de Sevilla y el obispado de Cádiz: imagen de un gran partido fiscal en la recaudación del pedido regio", Historia. Instituciones. Documentos, 40, pp. 361-395.

Veas Arteseros, Francisco de Asís (2003), Itinerario de Enrique III, Universidad de Murcia, Murcia.

Vilaplana Gisbert, Victoria J. (ed.) (1993), Colección de documentos para la historia del Reino de Murcia. Vol.15. Documentos de la minoría de Juan II. La regencia de Don Fernando de Antequera, Academia Alfonso $\mathrm{X}$ el Sabio, Murcia.

Villalobos Martínez-Pontremuli, María Luisa de (1983), "Las gestiones hacendísticas de Diego López de Estúñiga, camarero de Juan I: contribución al estudio de la economía y fiscalidad castellanas bajo los primeros Trastámaras", Hispania, 43, pp. 159-206. 